\title{
Dipodal Ferrocene-Based Adsorbate Molecules for Self-Assembled Monolayers on Gold
}

\author{
Tobias Weidner, ${ }^{[b]}$ Nirmalya Ballav, ${ }^{[b]}$ Michael Zharnikov, ${ }^{[b]}$ Andreas Priebe, ${ }^{[c]}$ \\ Nicholas J. Long, ${ }^{[\mathrm{d}]}$ Jörg Maurer, ${ }^{[\mathrm{e}]}$ Rainer Winter ${ }^{[\mathrm{e}]}$ Alexander Rothenberger, ${ }^{[\mathrm{f}]}$ \\ Dieter Fenske, ${ }^{[0]}$ Dag Rother, ${ }^{[\mathrm{a}]}$ Clemens Bruhn, ${ }^{[\mathrm{a}]}$ Heinrich Fink, ${ }^{[\mathrm{a}]}$ and \\ Ulrich Siemeling*[a]
}

\begin{abstract}
Difunctionalised ferrocene derivatives have been studied, which contain groups suitable for chemisorption on gold substrates, namely $-\mathrm{NC},-\mathrm{PR}_{2}$ as well as a range of sulfur-containing units like -NCS, $-S R$, and thienyl. Thin films on gold have been fabricated from solution with most of these adsorbate species. Film thickness, composition and structure were investigated primarily by $\mathrm{X}$ ray photoelectron and near-edge $\mathrm{X}$-ray
\end{abstract}

absorption fine-structure spectroscopy. The quality of self-assembled monolayers fabricated from 1,1'-diisocyanoferrocene (1) and 1,1'-diisothiocyanatoferrocene (2) turned out to be superior to that of films based on the other adsorbate species investigated. In addition to

Keywords: aurophilicity * iron . NEXAFS spectroscopy * S ligands . thin films the surface coordination behaviour of 1 towards gold substrates, relevant aspects of the molecular coordination chemistry of $\mathbf{1}$ have also been addressed, including the synthesis and characterisation of $\left[(\mu-1)\left\{\mathrm{Cr}(\mathrm{CO})_{5}\right\}_{2}\right]$, $\left[\mathrm{Ag}_{2}(\mu-1)_{2}\right]\left(\mathrm{NO}_{3}\right)_{2} \cdot \mathrm{H}_{2} \mathrm{O}$ and $[(\mu-1)-$ $\left.(\mathrm{AuCl})_{2}\right]$. The crystal structure of the gold complex is governed by aurophilic interactions and can be taken as a model for the arrangement of $\mathbf{1}$ in selfassembled monolayers on gold.

\section{Introduction}

[a] D. Rother, Dr. C. Bruhn, Dr. H. Fink, Prof. U. Siemeling Institute of Chemistry and Center for Interdisciplinary Nanostructure Science and Technology (CINSaT) University of Kassel, 34109 Kassel (Germany) Fax: (+49)561-804-4777 E-mail: siemeling@uni-kassel.de

[b] Dr. T. Weidner, Dr. N. Ballav. Dr. M. Zharnikov Applied Physical Chemistry University of Heidelberg, 69120 Heidelberg (Germany)

[c] Dr. A. Priebe Kirchhoff Institute for Physics University of Heidelberg, 69120 Heidelberg (Germany)

[d] Prof. N. J. Long Department of Chemistry Imperial College London, London SW7 2AZ (UK)

[c] Dr. J. Maurer, Prof. R. Winter Institute of Inorganic Chemistry University of Regensburg, 93040 Regensburg (Germany)

[f] Dr. A. Rothenberger, Prof. D. Fenske

Institute of Inorganic Chemistry University of Karlsruhe, 76131 Karlsruhe (Germany)
Self-assembled monolayers (SAMs) on solid surfaces are of great current interest in science and technology. ${ }^{[1]}$ SAMs formed by the aggregation of organosulfur compounds on gold have received most attention, ever since it was first reported that SAMs on gold can be prepared conveniently by chemisorption of di- $n$-alkyl disulfides or related cyclic derivatives from dilute solutions. ${ }^{[2]}$ Adsorbate molecules carrying terminal functional units can lead to functional SAMs. ${ }^{[\mathrm{b} . c]}$ Depending on the nature of the functional units, such SAMs can be utilised for diverse applications. For example, redoxactive adsorbate species based on tetrathiafulvalene, ${ }^{[3]}$ ferrocene and porphyrin ${ }^{[4]}$ have been widely used for electrode modification and related purposes. ${ }^{[5]}$ We have focused our attention on 1,1'-disubstituted ferrocene derivatives which contain two identical anchor groups suitable for chemisorption on gold and have already described results concerning SAM formation with 1,1'-diisocyanoferrocene (1), 1,1'-diisothiocyanatoferrocene (2) and 1,1'-bis(diphenylphosphanyl)ferrocene (dppf, 3) investigated in situ and in real time by second harmonic generation (SHG) ${ }^{[6]}$ Owing to a surface chelate effect, oligodentate adsorbate molecules can bind 
particularly strongly to a substrate. Even with relatively weak binding anchor units such as thioethers, ${ }^{[7]}$ stable and densely packed SAMs on gold have been achieved this way. We here describe the preparation of several new sulfur-containing 1,1'-disubstituted ferrocene derivatives, together with the results of a detailed investigation concerning the behaviour of these and related dipodal adsorbate molecules on gold. The ferrocene derivatives investigated in this study are shown here. Synthetic work and crystal structures will be dealt with first, followed by a surface science section focusing on film fabrication and characterisation.
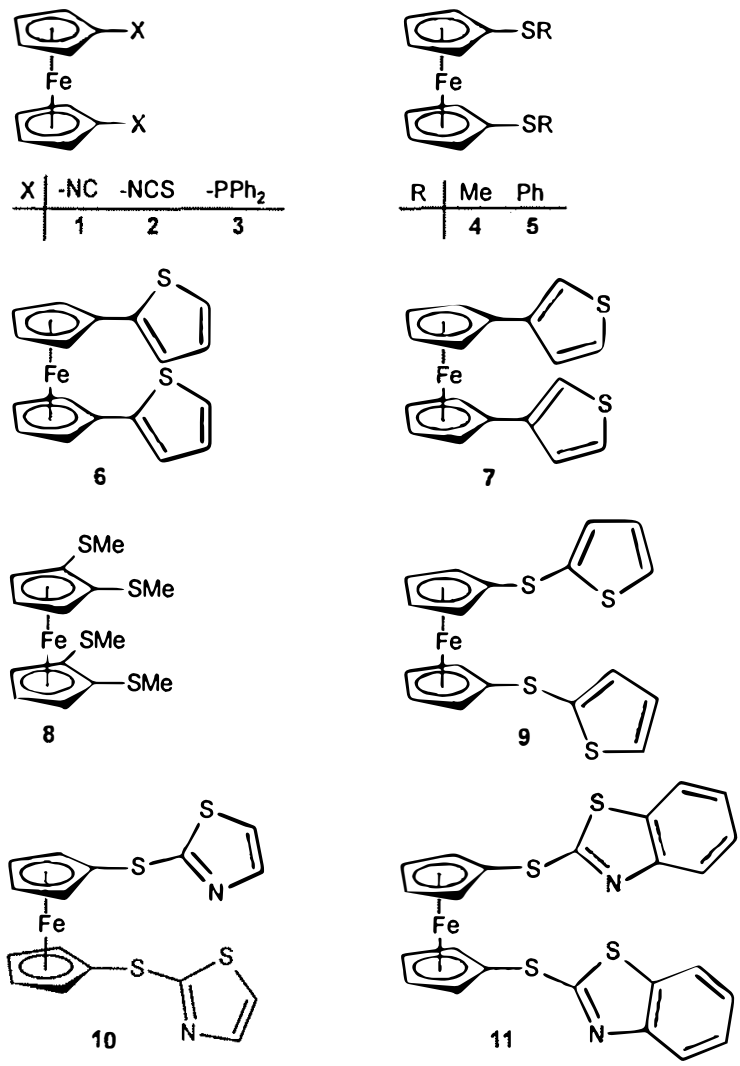

\section{Results and Discussion}

Synthesis and characterisation of compounds: The preparation of compounds 2, 7 and 9-11 has not been described before. 1,1'-Diisothiocyanatoferrocene (2), which is a sulfurextended analogue of 1,1'-diisocyanoferrocene (1), was obtained in good yield from the aza-Wittig reaction of $[\mathrm{Fe}-$ $\left.\left\{\mathrm{C}_{5} \mathrm{H}_{4}\left(\mathrm{~N}=\mathrm{PPh}_{3}\right)\right\}_{2}\right]^{[8]}$ with the heterocumulene $\mathrm{CS}_{2}{ }^{[9]} 1,1^{\prime}$ $\mathrm{Di}(3$-thienyl)ferrocene (7) was prepared by Negishi coupling of $\left[\mathrm{Fe}\left\{\mathrm{C}_{5} \mathrm{H}_{4}(\mathrm{ZnCl})\right\}_{2}\right]$ with 3-bromothiophene in analogy to the 2-thienyl analogue. ${ }^{[10]}$ The di(thioether) derivatives [Fe$\left.\left\{\mathrm{C}_{5} \mathrm{H}_{4}(\mathrm{SR})\right\}_{2}\right]($ 9: $\mathrm{R}=$ thien-2-yl, 10: $\mathrm{R}=$ thiazol-2-yl, 11: $\mathrm{R}=$ benzothiazol-2-yl) were obtained from the reaction of $1,1^{\prime}$ dilithioferrocene with the respective disulfide RSSR in analogy to the synthesis of $\left[\mathrm{Fe}\left\{\mathrm{C}_{5} \mathrm{H}_{4}(\mathrm{SPh})\right\}_{2}\right]$. $^{[1]}$
The crystal structures of the thien-2-yl-substituted compound $\mathbf{9}$, the thiazolyl-substituted derivative 10 (Figure 1) and the benzothiazolyl-substituted derivative 11 (Figure 2)

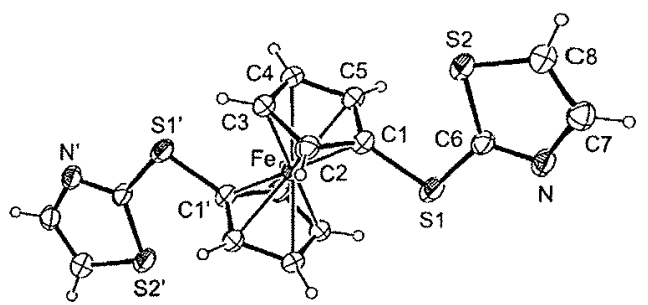

Figure 1. Molecular structure of $\mathbf{1 0}$ in the crystal. Selected bond lengths $[\AA]$ and angles $\left[{ }^{\circ}\right]: \mathrm{C} 1-\mathrm{S} 11.772(5), \mathrm{C} 6-\mathrm{S} 1$ 1.755(6), C6-S2 1.736(5), C6$\mathrm{N}$ 1.323(6), C7-N 1.378(8), C7-C8 1.382(8), C8-S2 1.731(6); C1-S1-C6 101.7(3), C6-S2-C8 89.4(3), C6-N-C7 110.2(4).

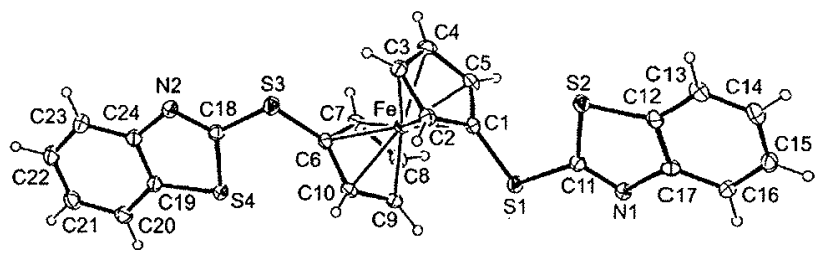

Figure 2. Molecular structure of $\mathbf{1 1}$ in the crystal. Selected bond lengths [Å] and angles [ ${ }^{\circ}$ ]: C1-S1 1.759(2), C6-S3 1.759(2), C11-S1 1.759(2), C11-N1 1.289(2), C11-S2 1.758(2), C12-S2 1.744(2), C12-C17 1.406(2), C17-N1 1.398(2), C18-S3 1.757(2), C18-N2 1.289(2), C18-S4 1.7552(17), C19-C24 1.399(2), C19-S4 1.744(2), C24-N2 1.398(2); C1-S1-C11 102.61(8), C11-S2-C12 88.29(8), C11-N1-C17 110.1(1), C6-S3-C18 101.88(8), C18-S4-C19 88.18(8), C18-N2-C24 109.8(2).

were determined by X-ray diffraction. In the case of $\mathbf{9}$, the quality of the crystal structure determination was severely affected by disorder (see the Supporting Information). Derivative $\mathbf{1 0}$ exhibits perfectly staggered cyclopentadienyl rings, which is owed to its crystallographically imposed centrosymmetric molecular structure. Bond parameters are unexceptional and compare well with those of related species such as, for example, $\left(\mathrm{RSCH}_{2} \mathrm{CH}_{2}\right)_{2},{ }^{[12]}\left(\mathrm{RSCH}_{2}\right)_{2}-p-\mathrm{C}_{6} \mathrm{H}_{4}{ }^{[13]}$ as well as $\mathrm{RSSR}(\mathrm{R}=$ thiazol-2-yl), the crystal structure of which was also determined as a sideline of our investigations (see the Supporting Information). The cyclopentadienyl rings of $\mathbf{1 1}$ are arranged in an essentially eclipsed orientation, as is usually the case for 1,1'-disubstituted ferrocene derivatives. Again, bond parameters are unexceptional and compare well with those of related species such as, for example, $\mathrm{RSMe}^{[14]}(\mathrm{RS})_{2} \mathrm{CH}_{2}$ and $\left(\mathrm{RSCH}_{2} \mathrm{CH}_{2} \mathrm{OCH}_{2}\right)_{2}(\mathrm{R}=$ benzothiazol-2-yl). ${ }^{[15]}$ Intermolecular $\mathrm{S}$...S distances close to the sum of the estimated van der Waals radii of $3.7 \AA^{[16]}$ are present in the crystal structures of RSSR ( $R=$ thiazol-2-yl), 10 and 11, as are typical for such sulfur-rich compounds. The origin of these S...S contacts is commonly attributed to weakly attractive interactions between the "soft" sulfur atoms.

We note that thiazolyl-substituted ferrocenes were recently utilised for selective ion sensing, ${ }^{[17]}$ whereas di(benzothia- 
zolyl)-substituted compounds in general are currently attracting increased attention as chelate ligands. ${ }^{[18]}$

The coordination chemistry of the new ligands described here has not been in the centre of our activities so far, but will be fully investigated in due course. As a prelude, we have already begun to study aspects of the coordination chemistry of $1,1^{\prime}$-diisocyanoferrocene (1).$^{[1]]}$ At the start of our work, the chemistry of $\mathbf{1}$, much to our surprise, was completely unexplored, whereas its monodentate analogue isocyanoferrocene (12) had already been investigated in detail. ${ }^{[20]}$ Analogue $\mathbf{1 2}$ was shown to behave like an aryl isocyanide in complexes like $\left[\operatorname{Cr}(12)_{6}\right]^{[20 b, c]}$ and $\left[\mathrm{Cr}(\mathbf{1 2})(\mathrm{CO})_{5}\right] .^{[20 e]} \mathrm{IR}$ spectroscopic data indicate that $\mathbf{1}$ behaves in an analogous fashion. It readily forms $\left[(\mu-1)\left\{\mathrm{Cr}(\mathrm{CO})_{5}\right\}_{2}\right]$ with two equivalents of $\left[\mathrm{Cr}(\mathrm{CO})_{5}(\mathrm{THF})\right]$, whereupon the $\bar{v}(\mathrm{NC})$ band shifts from 2118 to $2142 \mathrm{~cm}^{-1}$. This effect is similar to that observed in the case of $\left[\mathrm{Cr}(\mathbf{1 2})(\mathrm{CO})_{5}\right]$. . $^{[20 e]}$

$\left[(\mu-1)\left\{\mathrm{Cr}(\mathrm{CO})_{5}\right\}_{2}\right]$ was structurally characterised by X-ray diffraction (Figure 3). It exhibits an eclipsed orientation of the cyclopentadienyl rings with a synclinal arrangement of

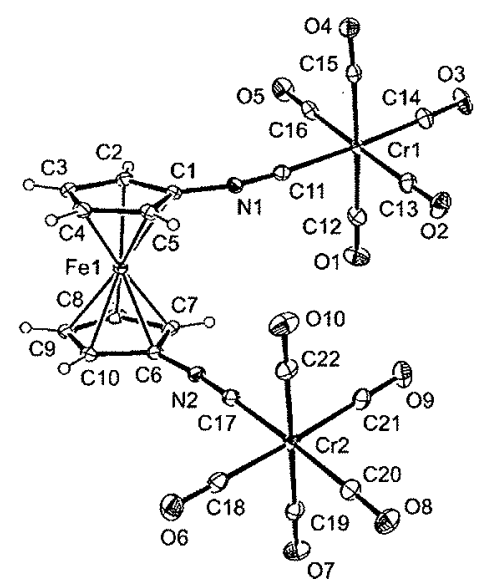

Figure 3. Molecular structure of $\left[(\mu-1)\left\{\mathrm{Cr}(\mathrm{CO})_{5}\right\}_{2}\right]$ in the crystal. Selected bond lengths $[\AA]$ and angles $\left[{ }^{\circ}\right]$ not discussed in the text: C1-N1 1.388(2), C6-N2 1.386(2); C1-N1-C11 170.2(2), C6-N2-C17 174.9(2).

the two substituents. The isocyanide $\mathrm{C}-\mathrm{Cr}$ bond lengths are 1.977(2) and 1.992(2) $\AA$, while the carbonyl $\mathrm{C}-\mathrm{Cr}$ bond lengths are noticeably shorter, ranging from $1.889(2)$ to 1.918(2) $\AA$. The isocyanide $\mathrm{N}-\mathrm{C}$ bond lengths are $1.160(2)$ and 1.154(2) $\AA$. The nitrogen bond angles of 170.2(2) and $174.9(2)^{\circ}$ are compatible with essentially sp-hybridised nitrogen atoms and rather weak $\pi$-backbonding from each $\mathrm{Cr}(\mathrm{CO})_{5}$ fragment, which is in line with the considerably lower $\pi$-acidity of isocyanides in comparison to $\mathrm{CO}$. It is instructive to compare these bond parameters to those reported by Shapiro et al. for the ansa-chromocene complex $\left[(\mu-1)\left\{\mathrm{Cr}\left[\mathrm{CMe}_{2}\left(\mathrm{C}_{5} \mathrm{H}_{4}\right)\right]_{2}\right\}_{2}\right] . .^{[20 a]}$ In this case the nitrogen bond angles are $126.4(3)$ and $126.8(3)^{\circ}$, which indicates a comparatively high degree of $\pi$-backbonding to 1 with essentially $\mathrm{sp}^{2}$-hybridised nitrogen atoms. This is further supported by the rather short $\mathrm{C}-\mathrm{Cr}$ bond lengths of 1.852(4) and $1.862(4) \AA$ and the rather long isocyanide $\mathrm{N}-\mathrm{C}$ bond lengths of 1.224(4) and 1.230(4) $\AA$. Not surprisingly, the homoleptic isocyanoferrocene complex $\left[\mathrm{Cr}(\mathbf{1 2})_{6}\right]$ adopts an intermediate position in terms of $\pi\left[\right.$-backbonding. ${ }^{[20 b]}$ This is reflected by average values for the $\mathrm{N}-\mathrm{C}$ and $\mathrm{C}-\mathrm{Cr}$ bond lengths of 1.178 and $1.937 \AA$, respectively, and an average $\mathrm{CrNC}$ angle of $161.5^{\circ}$, which in each case is intermediate between the corresponding values found for $\left[(\mu-\mathbf{1})\left\{\mathrm{Cr}(\mathrm{CO})_{5}\right\}_{2}\right]$ and $[(\mu-\mathbf{1})\{\mathrm{Cr}-$ $\left.\left.\left[\mathrm{CMe}_{2}\left(\mathrm{C}_{5} \mathrm{H}_{4}\right)\right]_{2}\right\}_{2}\right]$.

The electrochemical behaviour of 1 and $\left[(\mu-1)\left\{\mathrm{Cr}(\mathrm{CO})_{5}\right\}_{2}\right]$ was studied by cyclic voltammetry. The investigation was partially complicated by adsorption processes, which occurred at the electrode surface. For this reason, the oxidation of 1 proved to be irreversible $\left(E_{\mathrm{pa}}=0.63 \mathrm{~V}\right.$ vs. ferrocenium/ferrocene at $\left.0.10 \mathrm{Vs}^{-1}\right)$. The chromium complex $\left[(\mu-\mathbf{1})\left\{\mathrm{Cr}(\mathrm{CO})_{5}\right\}_{2}\right]$ exhibited a reversible ferrocene-based one-electron process at $E^{0 \prime}=0.55 \mathrm{~V}$ vs. ferrocenium/ferrocene, while the second oxidation was irreversible $\left(E_{\mathrm{pa}}=\right.$ $0.86 \mathrm{~V}$ vs. ferrocenium/ferrocene at $\left.0.10 \mathrm{Vs}^{-1}\right)$. Spectroelectrochemical investigations have revealed that oxidation of the ferrocene unit of $\left[(\mu-1)\left\{\mathrm{Cr}(\mathrm{CO})_{5}\right\}_{2}\right]$ leads to a shift of the isocyanide band from 2142 to $2017 \mathrm{~cm}^{-11}$ (Figure 4), a fact that can be explained by a decreased net electron donor ability of $1^{+}$. The pronounced $\bar{v}(\mathrm{NC})$ band shift upon oxidation of $\left[(\mu-1)\left\{\mathrm{Cr}(\mathrm{CO})_{5}\right\}_{2}\right]$ is fully in accord with results obtained with the related $\left[\mathrm{Cr}\left(\mathrm{Fc}-\mathrm{CH}_{2}-\mathrm{NC}\right)(\mathrm{CO})_{5}\right] .^{[20 \mathrm{e}]}$

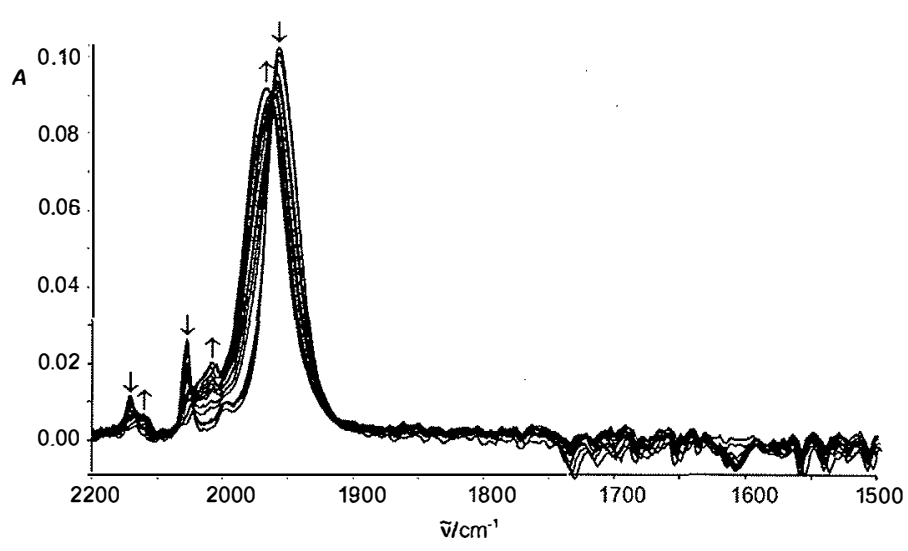

Figure 4. IR spectra recorded during electrochemical one-electron oxidation of $\left[(\mu-1)\left\{\mathrm{Cr}(\mathrm{CO})_{5}\right\}_{2}\right]$ in dichloromethane solution. Principal IR bands of $\left[(\mu-1)\left\{\mathrm{Cr}(\mathrm{CO})_{s}\right\}_{2}\right]: \bar{\nu}(\mathrm{NC}) 2142(\mathrm{w}) ; \bar{\nu}(\mathrm{CO}) 2055(\mathrm{~m}), 1957 \mathrm{~cm}^{-1}$ (vs). Principal IR bands of $\left[(\mu-1)\left\{\mathrm{Cr}(\mathrm{CO})_{s}\right\}_{2}\right]^{+}: \bar{\nu}(\mathrm{NC}) 2017(\mathrm{~m}) ; \bar{\nu}(\mathrm{CO}) 2121$ (w), $1967 \mathrm{~cm}^{-1}$ (vs)

The distance between the two Cp decks of ferrocene is $3.32 \AA$, and the molecule shows ball-bearing like features, as the barrier for ring rotation is very small. ${ }^{[21]}$ In view of these properties, an investigation of the coordination behaviour of 1 towards gold(I) seemed interesting, as in the solid state aurophilic interactions between neighbouring molecules in isocyanide gold(I) complexes can lead to intermolecular $\mathrm{Au}-\mathrm{Au}$ contacts below the sum of the estimated van der 
Waals radii $(3.6 \AA) \cdot{ }^{[22.23]}$ We envisaged that here intramolecular $\mathrm{Au}-\mathrm{Au}$ interactions lead to an unprecedented diaura[6]ferrocenophane. In general, two-coordinate gold(I) compounds experience attractive aurophilic interactions if the $\mathrm{Au}-\mathrm{Au}$ separations are below $3.6 \AA$; their strength can be up to $10 \mathrm{kcal} \mathrm{mol}^{-1}$ for a dimeric unit, similar to standard hydrogen bonds. ${ }^{[24]}$ The energetic contribution of longer $\mathrm{Au}-\mathrm{Au}$ contacts is negligible. ${ }^{[22 \mathrm{a}]}$ Aurophilic association can also lead to oligomers and one- and two-dimensional polymers.

In comparison to ligands like $\mathrm{R}_{3} \mathrm{P}, \mathrm{R}_{2} \mathrm{~S}$, etc., isocyanides appear to weaken aurophilic bonding in gold(I) compounds, ${ }^{[25 a]}$ as witnessed by $\mathrm{Au}-\mathrm{Au}$ separations close to the threshold value of $3.6 \AA .^{[23.25]}$ Particularly short distances between $[\mathrm{AuX}(\mathrm{RNC})]$ molecules have been observed for species which form dimeric aggregates in the solid state. The shortest $\mathrm{Au}-\mathrm{Au}$ distance has been reported for the alkyl isocyanide complex $\left[\mathrm{AuCl}\left(\mathrm{TosCH}_{2} \mathrm{NC}\right)\right][3.0634(4) \AA]$, ${ }^{[26]}$ whereas the shortest such distance for an aryl isocyanide complex has been observed for [AuCl(MesNC)] $[3.336(1) \AA]{ }^{[238]}$ Gold(I) complexes of oligodentate isocyanides are rare. The only compound of this type which shows some evidence for intramolecular $\mathrm{Au}-\mathrm{Au}$ interactions is [ $\mu$ $\left.\mathrm{dmb})(\mathrm{AuCN})_{2}\right] \quad\left(\mathrm{dmb}=1,8\right.$-diisocyano-p-menthane). ${ }^{[27]}$ The isocyanide groups are located on the same side of the $\mathrm{dmb}$ ligand, binding two $\mathrm{AuCN}$ units with an $\mathrm{Au}-\mathrm{Au}$ separation of 3.54(1) $\AA$. The molecules are aggregated into antiparallel dimers with intermolecular $\mathrm{Au}-\mathrm{Au}$ distances of $\approx 3.49 \AA$.

The reaction of $1,1^{\prime}$-diisocyanoferrocene (1) with [AuCl$\left.\left(\mathrm{SMe}_{2}\right)\right]$ in dichloromethane afforded $\left[(\mu-1)(\mathrm{AuCl})_{2}\right]_{n}$, irrespective of the applied ratio of the reactants $(1: 1$ or $1: 2)$. The compound precipitated immediately upon addition of the first drop of reagent solution, irrespective of whether 1 was added to $\left[\mathrm{AuCl}\left(\mathrm{SMe}_{2}\right)\right]$ or vice versa. $\left[(\mu-1)(\mathrm{AuCl})_{2}\right]_{n}$ proved to be insoluble in all common solvents, including hot acetonitrile, pyridine, 1,2-dichloroethane, dimethyl sulfide as well as DMSO and DMF. The interaction of 1 with the $\mathrm{AuCl}$ units leads to a pronounced shift of the isocyanide band from 2142 to $2226 \mathrm{~cm}^{-1}$. The polymer undergoes ligand substitution with $t \mathrm{BuNC}$ and $\mathrm{Ph}_{3} \mathrm{P}$ in dichloromethane, liberating uncoordinated 1 . Small single crystals of $[(\mu-1)$ $\left.(\mathrm{AuCl})_{2}\right]_{n}$ were obtained by layering a dichloromethane solution of $\left[\mathrm{AuCl}\left(\mathrm{SMe}_{2}\right)\right]$ in a $5 \mathrm{~mm} \mathrm{NMR}$ tube with neat dichloromethane and then with a dichloromethane solution of 1. Numerous attempts were necessary to obtain crystals suitable for a single-crystal X-ray diffraction study, the result of which is shown in Figure 5. Owing to the small size of the crystal, the quality of the crystal structure determination is sufficient for a meaningful discussion of the bond parameters of the heavy atoms only.

The molecules adopt the anticipated 3,4-diaura-[6]ferrocenophane structure. The intramolecular $\mathrm{Au}-\mathrm{Au}$ distance is 3.336(1) $\AA$, which is essentially identical to the distance between the $\mathrm{Cp}$ rings in ferrocene and with the $\mathrm{Au}-\mathrm{Au}$ separation observed for [ $\mathrm{AuCl}(\mathrm{MesNC})]$ (see above). The $\mathrm{Au}-\mathrm{Cl}$ distances of 2.274(5) and 2.280(5) $\AA$ are indistinguishable within experimental error from the value of $2.262(3) \AA$ re-

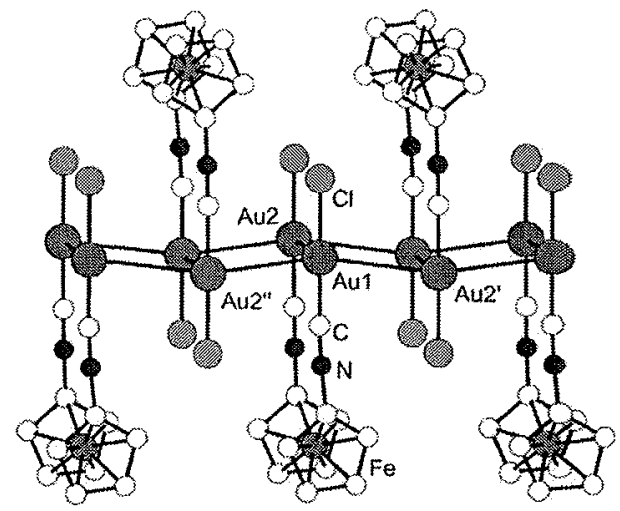

Figure 5. View of the association of $\left[(\mu-1)(\mathrm{AuCl})_{2}\right]$ in the crystal. Selected bond lengths $[\AA ̊]$ : Au1--Au2 3.336(1). Au1-Au2' 3.484(1), Au1-Au2" 3.354(1) (Au2': $2-x, 1-y, 1-z ;$ Au2": $1-x, 1-y, 1-z$ ).

ported for $[\mathrm{AuCl}(\mathrm{MesNC})]$. [ $\mathrm{AuCl}(\mathrm{MesNC})]$ aggregates into dimers, whereas the $\left[(\mu-\mathbf{1})(\mathrm{AuCl})_{2}\right]$ units form one-dimensional chains. The zipper-like arrangement of the molecules leads to a corrugated ribbon of gold atoms composed of two parallel chains, each exhibiting alternating $\mathrm{Au}-\mathrm{Au}$ distances of 3.354(1) and 3.484(1) $\AA$.

The structural and functional similarities of aurophilic and hydrogen bonding have been emphasized in recent studies. ${ }^{[28]}$ In particular, a striking structural similarity between isocyanide complexes $\mathrm{Me}\left(\mathrm{CH}_{2}\right)_{n-1} \mathrm{NCAuCl}$ and primary alcohols $\mathrm{Me}\left(\mathrm{CH}_{2}\right)_{n} \mathrm{OH}$ has been pointed out. ${ }^{[25 b]}$ In this context, we note that the conformation and aggregation of the $\left[(\mu-1)(\mathrm{AuCl})_{2}\right]$ units closely resemble that of $\left[\mathrm{Fe}\left\langle\mathrm{C}_{5} \mathrm{H}_{4}-\right.\right.$ $\left.(\mathrm{CHMeOH})\}_{2}\right]$, in which intramolecular hydrogen bonding occurs between the two alcoholic substituents; the molecules are aggregated into one-dimensional chains through intermolecular hydrogen bonds, with an antiparallel zipper-like arrangement of neighbouring molecules. ${ }^{[29]}$

The insoluble nature of $\left[(\mu-1)(\mathrm{AuCl})_{2}\right]_{n}$ is unique for compounds of this kind and, in conjunction with the structural data, indicative of an effective balance between intra- and intermolecular aurophilicity. In view of the great current interest in metal-containing polymers,${ }^{[30]}$ we note that $[(\mu-1)$ $\left.(\mathrm{AuCl})_{2}\right]_{n}$ is a new type of polymer with precious metal atoms in the backbone. ${ }^{[31]}$

The intriguing results obtained in the chemistry of gold(I) prompted us to turn our attention to silver(I), whose isocyanide coordination chemistry has been somewhat overshadowed by that of its heavier congener. The first report concerning this class of compounds comes from the year 1952 and describes the preparation of $\left[\mathrm{Ag}(p \text {-Tol-NC })_{4}\right]-$ $\left(\mathrm{NO}_{3}\right) \cdot \mathrm{H}_{2} \mathrm{O}$ from $\mathrm{AgNO}_{3}$ and $p$-tolyl isocyanide, together with the formation of $\left[\mathrm{Ag}(p-\mathrm{Tol}-\mathrm{NC})_{2}\right]\left(\mathrm{NO}_{3}\right)$ from this product during its recrystallisation from $\mathrm{CHCl}_{3} / \mathrm{Et}_{2} \mathrm{O}^{[32]}$ This earliest example already nicely reflects a fundamental feature of silver(I) isocyanide complexes in comparison to related gold(I) compounds. The structures of the silver(I) species are more flexible, with the $\mathrm{Ag}$ atoms often being tri- or tetra-coordinate. Quasilinear two-coordination of the metal 
by isocyanide ligands, which is the rule for gold(I), is the exception for silver(I), where usually strong interactions with the anion are observed. ${ }^{[33]}$ The reaction of $\mathbf{1}$ with $\mathrm{AgNO}_{3}$ in a 1:1 ratio in acetonitile afforded the 3,3'-diargenta[5.5]ferrocenophane derivative $\left[\mathrm{Ag}_{2}(\mu-1)_{2}\right]\left(\mathrm{NO}_{3}\right)_{2}$, which was isolated as shiny golden platelets. Owing to silver(I) coordination, the 'H NMR signals of $\mathbf{1}$ are shifted considerably from $\delta=4.26$ and 4.63 (uncoordinated 1 ) to $\delta=4.47$ and $5.30 \mathrm{ppm}$ in $\mathrm{CDCl}_{3}$. The IR spectrum of $\left[\mathrm{Ag}_{2}(\mu-1)_{2}\right]\left(\mathrm{NO}_{3}\right)_{2}$ exhibits a single $\bar{\nu}(\mathrm{NC})$ band, which is located at $2193 \mathrm{~cm}^{-1}$. The coordination-induced $\bar{v}(\mathrm{NC})$ band shift is $34 \mathrm{~cm}^{-1}$ less than that observed in the case of the gold complex $[(\mu-1)$ $\left.(\mathrm{AuCl})_{2}\right]_{n}$ (see above), which is fully in accord with results of a recent study which compares such band shifts for a variety of gold and silver complexes. ${ }^{[34]}$

Crystals suitable for a single-crystal X-ray diffraction study were obtained by recrystallisation from dichloromethane and turned out to contain one additional water molecule per formula unit. Two independent $\left[\mathrm{Ag}_{2}(\mu-1)_{2}\right]^{2+}$ species (A and $\mathrm{B}$ ) are present in the crystal, whose bond parameters are very similar. The water molecule is disordered over two sites. It acts as a bridging ligand and connects neighbouring $\mathrm{A}$ and $\mathrm{B}$ species which alternate in the resulting polymeric chain $\left[\mathrm{A}\left(\mu-\mathrm{H}_{2} \mathrm{O}\right) \mathrm{B}\left(\mu-\mathrm{H}_{2} \mathrm{O}\right)\right]_{n}$. This $\mu_{2}$ coordination mode of water is unusual, but not unprecedented, in the chemistry of silver(I). ${ }^{[35]}$ The silver-coordinated water forms hydrogen bridges with one of the two nitrate anions. This anion is disordered over two sites with split positions for the $\mathrm{O}$ atoms in each case. Figure 6 shows the molecular structure of an $\mathrm{A}\left(\mu-\mathrm{H}_{2} \mathrm{O}\right) \mathrm{B}$ unit, indicating a section of the polymeric chain.

Each silver atom strongly interacts with two isocyanide carbon atoms and one water oxygen atom. $\mathrm{The} \mathrm{Ag}-\mathrm{O}$ dis-

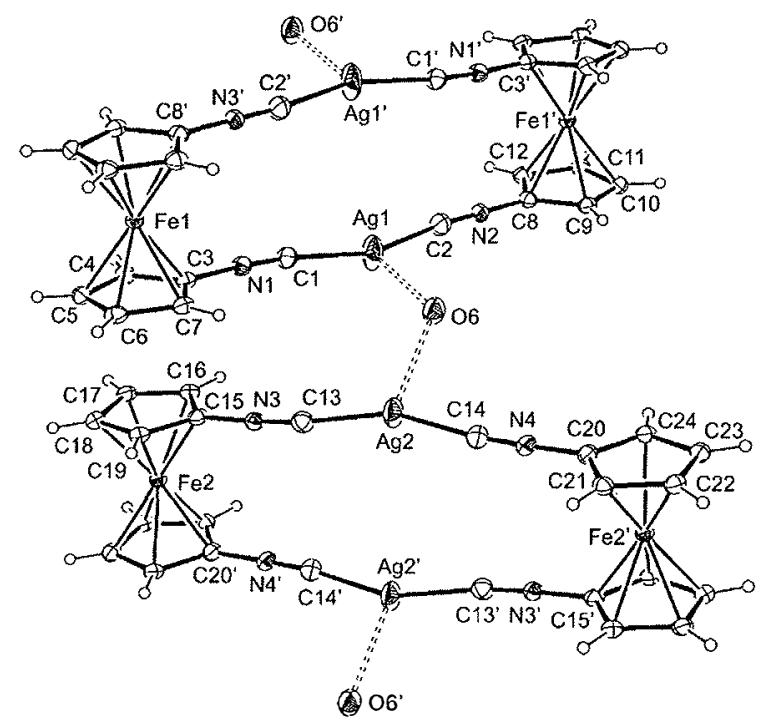

Figure 6. View of the association of $\left[\mathrm{Ag}_{2}(\mu-1)_{2}\right]\left(\mathrm{NO}_{3}\right)_{2} \cdot \mathrm{H}_{2} \mathrm{O}$ in the crystal. The nitrate anions are not shown. Selected bond lengths $[\AA]$ not discussed in the text: C3-N1 1.407(7), C8-N2 1.387(7), C15-N3 1.390(7), C20-N4 1.378(7). tances are $\approx 2.50 \AA$, which compares well to the value of 2.468(3) $\AA$ reported for the isocyanide complex [Ag(OTf) $\left.\left(\mu-4-\mathrm{NC}-3,5-i \mathrm{Pr}_{2}-\mathrm{C}_{6} \mathrm{H}_{2}-\mathrm{NC}\right)\right]_{n}^{[36]}$ as well as to the $\mathrm{Ag}-$ $\mathrm{OH}_{2}$ distances of 2.482(5), 2.50(1) and 2.51(1) $\AA$ found for the three-coordinate $\mathrm{Ag}$ atoms in the $\mu$-aqua complex $\left[\mathrm{Ag}_{8}-\right.$ $\left.\left(\mu_{3}-\mathrm{hmt}\right)_{2}\left(\mu_{4}-\mathrm{hmt}\right)_{2}(\mu-\mathrm{btc})_{2}\left(\mu-\mathrm{H}_{2} \mathrm{O}\right)_{3}\right] \cdot 18 \mathrm{H}_{2} \mathrm{O} \quad(\mathrm{hmt}=$ hexamethylenetetramine, btc $=1,2,4,5$-benzenetetracarboxylate $)^{[35]}$ It is also in the same range as the short $\mathrm{Ag}-\mathrm{O}$ contacts typically found in salts with oxyanions. ${ }^{[37]}$ The closest $\mathrm{Ag} \cdots \mathrm{O}$ contact which involves a nitrate anion is $\approx 2.8 \AA$ and therefore represents a rather weak, but non-negligible, interaction by commonly accepted criteria. ${ }^{[38]} \mathrm{The} \mathrm{Ag}$ atom is therefore embedded in a $3+1$ coordination environment. The $\mathrm{Ag}-\mathrm{C}$ and $\mathrm{N}-\mathrm{C}$ bond lengths are $\approx 2.09 \AA$ and $1.15 \AA$, respectively, which is similar to the corresponding values reported for closely related complexes such as, for example, $\left[\mathrm{Ag}\left(\kappa^{2}-\right.\right.$ $\left.\left.\mathrm{NO}_{3}\right)\left(\mathrm{TosCH}_{2} \mathrm{NC}\right)_{2}\right]$ [2.106(4) $\AA$; $\left.1.133(4) \AA\right]$, ${ }^{[33 \mathrm{a}]}\left[\mathrm{Ag}_{2}\left(\mu, \kappa^{1}-\right.\right.$ $\left.\left.\mathrm{NO}_{3}\right)_{2}(\mu-\mathrm{dmb})_{2}\right][2.084(7) \AA ; 1.132(11)$ and $1.089(17) \AA],{ }^{[39]}$ $\left[\mathrm{Ag}\left(4-\mathrm{NC}-3,5-i \mathrm{Pr}_{2}-\mathrm{C}_{6} \mathrm{H}_{2}-\mathrm{NC}\right)_{2}\right]\left[\mathrm{BF}_{4}\right] \quad[2.092(5) \quad$ and $2.098(5) \AA ; 1.125(6)$ and 1.128(6) $\AA],{ }^{[36]}$ and $\left[\mathrm{Ag}\left(2,4,6-t \mathrm{Bu}_{3}-\right.\right.$ $\left.\left.\mathrm{C}_{6} \mathrm{H}_{2}-\mathrm{NC}\right)_{2}\right]\left[\mathrm{PF}_{6}\right]$ [2.075(14) $\AA$; 1.148(17) $\left.\AA\right] .{ }^{[40]}$ The C-N-C$\mathrm{Ag}$ units deviate slightly from linearity, the nitrogen bond angles and $\mathrm{N}-\mathrm{C}-\mathrm{Ag}$ angles ranging from $172.3^{\circ}$ to $173.6^{\circ}$ and from $171.6^{\circ}$ to $173.5^{\circ}$, respectively. In contrast, the $\mathrm{C}-\mathrm{Ag}-\mathrm{C}$ angles of $158^{\circ}$ and $160^{\circ}$ are considerably smaller than $180^{\circ}$, which is owed to the additional interaction of the $\mathrm{Ag}$ atom with the water oxygen atom. The $\mathrm{Ag}-\mathrm{O}-\mathrm{Ag}$ bond angle is $120^{\circ}$ and $124^{\circ}$, respectively, for the two disordered sites.

Film preparation and characterisation: Most of the adsorbate species (namely 1-8, see above) have been used for the fabrication of molecular films on gold, which were prepared at room temperature by immersion of the substrate in a dilute (typically $\approx 10 \mu \mathrm{M}$ ) solution of the respective adsorbate species for several hours. Acetonitrile and especially ethanol proved to be the preferred solvents. For example, according to near-edge X-ray absorption fine structure (NEXAFS) data 1 did not form well oriented SAMs from DMF, whereas from ethanol no such problems occurred. These observations are in line with results of a recent systematic investigation concerning the solvent influence on SAM quality by Witte and coworkers. ${ }^{[4]}$

SAM fabrication with isocyanides ${ }^{[42]}$ and thioethers ${ }^{[43]}$ on gold is well known. ${ }^{[16]}$ SAM formation of thiophene and its oligomers on gold, which was first reported in 1996 for pristine thiophene in contradiction to theoretical predictions, ${ }^{[44]}$ is of great current interest, as the corresponding films are potentially useful for electronic devices owing to high electronic conductivity ${ }^{[45]}$ However, SAM formation of thiophene derivatives continues to be a matter of debate, as conflicting reports concerning the mechanism of chemisorption, growth morphology as well as the structure, integrity and stability of the resulting SAMs exist in the recent literature. ${ }^{[46]}$ Isothiocyanates have not yet been investigated in detail in this context, and we are aware of only one report addressing this issue, utilising, however, gold nanoparticles and not solid gold substrates. ${ }^{[47]}$ On the basis of surface-en- 
hanced Raman scattering (SERS) data, the author comes to the conclusion that aromatic isothiocyanides have vertical stances on gold, binding through the sulfur atom. A similar lack of knowledge can be noted for SAMs on gold based on phosphanes, although phosphane-protected gold nanoparticles are ubiquitous. Again, we are aware of only a single relevant report. Persson and coworkers have investigated the chemisorption of tertiary phosphanes on several coinage and platinum metals and found multilayer formation from solution. After removal of physisorbed $\mathrm{PR}_{3}$ by ultrasonic treatment, the analysis of the remaining thin film by infrared reflection absorption spectroscopy (IRRAS) suggested binding of the adsorbate molecules to the metal surface by the phosphorus atom, similar to metal coordination in molecular chemistry. ${ }^{[48]}$

The identity, composition, integrity, and structure of all target films were investigated by two complementary experimental techniques, namely X-ray photoelectron spectroscopy (XPS) and NEXAFS spectroscopy. In view of the heterogeneity of the target systems we abstain from the presentation of the entire set of the experimental data, but present only selected spectra and respective numerical parameters in tabular form. As the first step, we describe the available experimental data and make general statements on their interpretation and respective implications. Most of these implications refer to all the systems of this study. Further, we consider the specific results for every particular system.

XPS gives quantitative information about the composition, chemical identity, and effective thickness of the target films. For the sake of brevity, a film fabricated from adsorbate species $\boldsymbol{n}$ will be termed "film $\boldsymbol{n}$ " $(\boldsymbol{n}=\mathbf{1 - 8})$ in the following. The relevant adsorbate molecules $1-8$ consist mostly of carbon and hydrogen and also contain iron as well as sulfur, phosphorus and nitrogen, depending on the individual molecular composition. The observation of the characteristic photoemission peaks assigned to the latter atoms is a fingerprint for the presence of the respective adsorbate species in the derived films, whereas the respective binding energies provide information on the chemical integrity and bonding configuration of the film constituents. The total in-

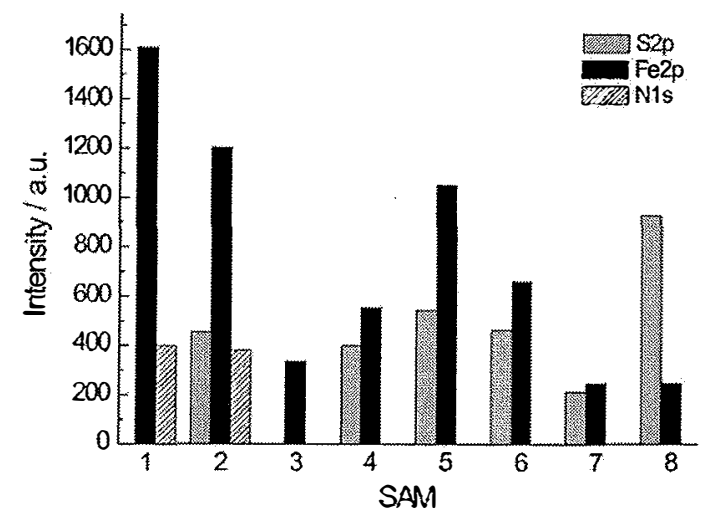

Figure 7. Normalised total intensities of the $S 2 p, N$ s, and Fe $2 p$ XP spectroscopic signals in the films 1-8. tensities of the $S 2 p, N 1 s$, and $F e 2 p$ signals in the various films investigated are summarized in Figure 7 and the binding energy (BE) positions of the respective emissions (and of the $\mathrm{P} 2 \mathrm{p}_{3 / 2}$ peak in the case of film 3 ) are shown in Table 1

Table 1 . Binding energy positions $[\mathrm{eV}]$ and $\mathrm{fwhm}[\mathrm{eV}]$ (in parentheses) of the $S 2 p_{3 / 2}, \mathrm{~N} 1 \mathrm{~s}, \mathrm{P} 2 \mathrm{p}_{3 / 2}$ and $\mathrm{Fe} 2 \mathrm{p}_{3 / 2}$ photoemission peaks for the films 1-8 along with the respective film thickness values [ $\mathrm{nm}]$.

\begin{tabular}{lllll}
\hline Film & $\mathrm{S} \mathrm{2}_{3 / 2}$ & $\mathrm{~N} 1 \mathrm{~s} / \mathrm{P} \mathrm{2 \textrm {p } _ { 3 2 }}$ & $\mathrm{Fe} 2 \mathrm{p}_{3 / 2}$ & Thickness \\
\hline $\mathbf{1}$ & & $399.9(2.8)$ & $708.1(1.9)$ & 14.3 \\
$\mathbf{2}$ & $161.7(2.1)$ & $399.8(3.3)$ & $707.9(2.0)$ & 9.6 \\
$\mathbf{3}$ & & $131.1(1.0)$ & $708.3(1.7)$ & 9.6 \\
$\mathbf{4}$ & $162.3(2.1)$ & & $707.9(1.7)$ & 6.8 \\
& $163.5(2.1)$ & & & \\
$\mathbf{5}$ & $163.2(1.9)$ & & $707.7(1.7)$ & 8.5 \\
& & & $712.0(1.7)$ & \\
$\mathbf{6}$ & $162.1(2.1)$ & & $707.8(1.7)$ & 6.7 \\
& $163.6(2.1)$ & & $711.5(1.7)$ & \\
$\mathbf{7}$ & $161.9(1.6)$ & & $707.8(1.7)$ & 8.2 \\
$\mathbf{8}$ & $163.6(1.6)$ & & & \\
\hline
\end{tabular}

All films exhibit an iron signal (even though with different intensities) with a characteristic $\mathrm{BE}$ of about $708 \mathrm{eV}$, this implies the chemisorption of the respective ferrocene-based adsorbate molecules on the gold substrate. For films $\mathbf{5}$ and 6, this signal is accompanied by additional $\mathrm{Fe} 2 \mathrm{p}$ emission at a higher $\mathrm{BE}(\approx 712 \mathrm{eV})$, which can be related to the partial oxidation and decomposition of the organometallic moieties in the above molecules. Note that the intensity of the Fe $2 p$ signal can be considered as a direct measure of the ferrocene-type content in the films, since the organometallic moieties comprise the film-ambient interface and are almost unaffected by attenuation effects typical for photoemission. Further, all the films, except 3, exhibit either sulfur or nitrogen signals (film 2 show both signals), in accordance with the molecular composition. The analysis of the BE positions of the $S 2 p, P 2 p_{3 / 2}$, and $\mathrm{N} 1 \mathrm{~s}$ emissions gives valuable information about the bonding configuration of the molecular adsorbates in the respective films. This analysis will be performed below as soon as the individual films will be considered. The $S 2 p$ XP spectra of the sulfur-containing films (2, 4-8) are presented in Figure 8. The $\mathrm{N} 1 \mathrm{~s}$ and $\mathrm{P} 2 \mathrm{p}_{3 / 2} \mathrm{XP}$ spectra of films 1,2 and 3 , respectively, exhibit only one emission (with parameters given in Table 1) and are therefore not presented.

Along with the $\mathrm{Fe}$ signal, the amount of the adsorbate molecules in the derived films is represented by the effective film thickness. The respective values were obtained from the $\mathrm{C} 1 \mathrm{~s} / \mathrm{Au} 4 \mathrm{f}$ intensity ratios, ${ }^{[49]}$ using previously reported attenuation lengths. ${ }^{[50]}$ Pertinent data are collected in Table 1. Whereas the thicknesses are quite small in each case, indicative of the formation of monolayer films, they do not fully correlate with the respective $\mathrm{Fe} 2 p_{3 / 2}$ intensities (Figure 7), even if one corrects for the different iron/carbon ratio in the adsorbate molecules. This suggests that part of the carbon 


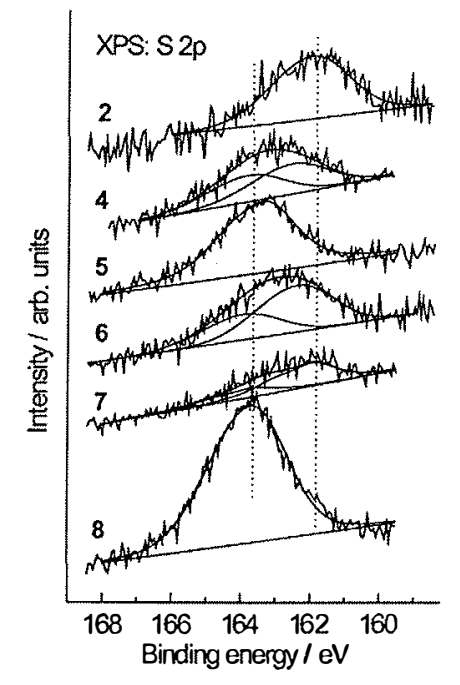

Figure 8. Normalised S $2 p$ XP spectra of films 2 and 4-8. The decomposition of the spectra into the individual components is shown. A background is drawn.

signal may originate from hydrocarbon contamination, which was initially present on the gold surface, and, presumably, not completely removed upon the chemisorption of the adsorbate molecules.

Complementary information on the composition and chemical identity of the films investigated is provided by the NEXAFS data. Generally, NEXAFS spectra give an insight into the electronic structure of target films, sampling the electronic structure of the unoccupied molecular orbitals of the film constituents. ${ }^{[51]}$ The iron $L$-edge spectra of films 1-8 recorded at the magic angle of $\mathrm{X}$-ray incidence $\left(55^{\circ}\right.$, at this orientation the spectrum is independent of the molecular orientation) are presented in Figure 9. These spectra were normalised to the pre-edge intensity and are therefore representative for the amount of iron in the target films. The spectra of all films exhibit the characteristic $\pi^{*}$ resonances

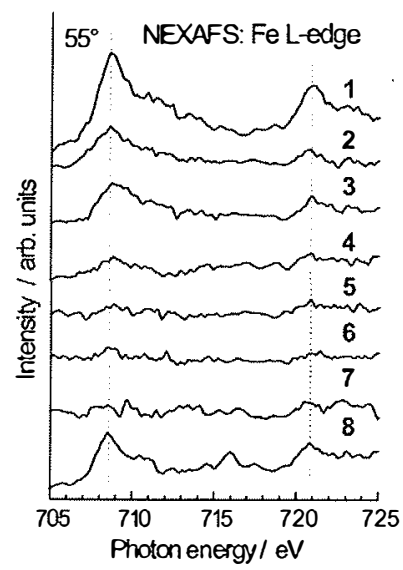

Figure 9. Normalised iron $L$-edge NEXAFS spectra of films 1-8 acquired at $\mathrm{X}$-ray incidence angles of $55^{\circ}$. related to the $4 \mathrm{e}_{1 \mathrm{~g}}$ and $3 \mathrm{e}_{2 \mathrm{u}}$ orbitals of ferrocene at both $L_{2-}$ and $L_{3}$-edges, ${ }^{[52]}$ suggesting the chemisorption of the adsorbate molecules on the gold substrate and therefore supporting the XPS results. The intensity of these resonances varies significantly from film to film, correlating roughly with the intensity of the XPS Fe $2 p$ signal.

The carbon $K$-edge spectra of films 1-8 recorded at the magic angle of $\mathrm{X}$-ray incidence are shown in Figure 10. These spectra exhibit a $\mathrm{C}$ 1s absorption edge ascribed to the

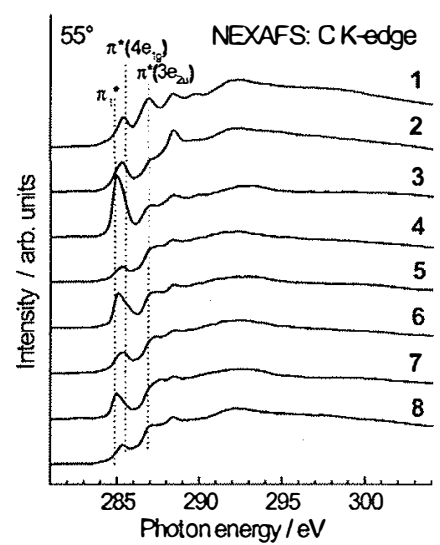

Figure 10. Carbon $K$-edge NEXAFS spectra of films 1-8 acquired at Xray incidence angles of $55^{\circ}$. Prominent absorption resonances are indicated. The dotted lines are a guide for the eyes.

$\mathrm{C} 1 \mathrm{~s} \rightarrow$ continuum excitations and a series of absorption resonances characteristic of the adsorbate molecules on the surface.

Most of the spectra exhibit the characteristic $\pi^{*}$ resonances related to the $4 \mathrm{e}_{1 \mathrm{~g}}$ and $3 \mathrm{e}_{2 \mathrm{u}}$ orbitals of ferrocene at 285.6 and $287.2 \mathrm{eV}$, respectively, and a broad $\sigma^{*}$ resonance of this organometallic moiety at $\approx 292 \mathrm{eV}^{[53]}$ For films $\mathbf{3}$ and $\mathbf{5}$, which contain phenyl rings, the corresponding characteristic $\pi_{1}^{*}$ resonance at $285.1 \mathrm{eV}$ is unequivocally observed. The characteristic $\pi^{*}$ resonance of an intact thiophene-type moiety (films 6 and 7) is expected at $285.6 \mathrm{eV}$, overlapping, however, with the $\pi^{*}\left(4 \mathrm{e}_{1 \mathrm{~g}}\right)$ resonance of the ferrocene nucleus. Furthermore, the $\sigma^{*}(\mathrm{C}-\mathrm{S}), \sigma^{*}(\mathrm{C}-\mathrm{N})$, or $\sigma^{*}(\mathrm{C}-\mathrm{P})$ resonances can in principle be observed at $\approx 287 \mathrm{eV},{ }^{[51]}$ but they are presumably weak and therefore not distinguishable from the $\pi *\left(3 e_{2 u}\right)$ resonance of the ferrocene nucleus in most of the spectra. Finally, a $\pi^{*}$-like resonance at $288.6 \mathrm{eV}$ observed in some spectra in Figure 10 can be alternatively assigned to conjugation phenomena (see below) or contamination $(\mathrm{CO})$.

In addition to the insight into the electronic structure of the target systems, NEXAFS data provide valuable information on the orientation of the film constituents, as the crosssection of the resonant photoexcitation process depends on the orientation of the electric field vector of the linearly polarized synchrotron light with respect to the transition dipole moment (TDM) of the probed molecular orbital. This effect is called linear dichroism in X-ray absorption. 
For ordered molecular films, the intensity of the absorption resonances changes at a variation of the incidence angle of the synchrotron light. A convenient way to monitor these changes is the difference between the spectra acquired at normal $\left(90^{\circ}\right)$ and grazing $\left(20^{\circ}\right)$ incidence. Such carbon $K$ edge difference spectra for films 1-8 are displayed in Figure 11. We note that the transition dipole moment of the

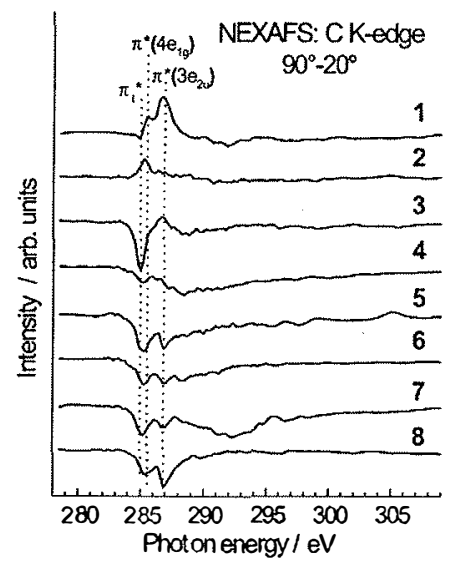

Figure 11. Carbon $K$-edge NEXAFS difference spectra of films 1-8. The curves represent the difference between the spectra acquired at X-ray incidence angles of $90^{\circ}$ and $20^{\circ}$. The position of the prominent absorption resonances are indicated by dotted lines.

$\pi^{*}$ orbitals is oriented perpendicular to the plane of the $\mathrm{C}_{5}$ rings and to the NC axis in $\mathbf{1}$ and 2 . The respective resonances are usually quite sharp, which makes monitoring of the linear dichroism easier as in the case of $\sigma^{*}$ resonances, which are commonly observed as broad features.

In the following we will discuss the experimental data for the individual films in more detail. These films differ, inter alia, in the headgroups that provide the anchoring to the gold substrate, giving rise to the following categories: isocyanide-based film 1 , isothiocyanate-based film 2 , phosphanebased film 3, thioether-based films 4,5 and 8 , and thiophene-based films 6 and 7.

Film 1: This film shows the highest $\mathrm{Fe}$ signal both in $\mathrm{XP}$ (Figure 7) and NEXAFS spectra (Figure 9) and thus exhibits the highest packing density of organometallic moieties among the systems investigated in this study. This agrees well with the highest effective thickness as shown in Table 2. Both carbon $K$-edge and iron $L$-edge spectra of film 1 exhibit intense resonance structure, characteristic of intact ferrocene-type units, suggesting non-dissociative chemisorption of the adsorbate molecules.

In XPS, only a single $\mathrm{N}$ 1s emission related to the isocyanide nitrogen appears at $399.9 \mathrm{eV},{ }^{[54]}$ indicating an exclusive isocyanide-mediated bidentate bonding of $\mathbf{1}$ to the Au substrate with no contributions from monodentate binding or physisorption. This interpretation is strongly supported by IRRAS data, which also suggest an essentially vertical orientation of the adsorbate molecules on the gold surface. Comparison of the spectra obtained with the modified gold substrate and those obtained from neat 1 reveals characteristic differences. The intensities of the out of plane $\delta(\mathrm{CH})$ bands at 1040, 1028 and $817 \mathrm{~cm}^{-1}$ are decreased almost below noise level. This confirms essentially parallel orientation of the cyclopentadienyl ring plane with respect to the

Table 2. X-ray crystallographic data.

\begin{tabular}{|c|c|c|c|c|c|}
\hline Compound & $\begin{array}{l}\text { RSSR } \\
(\mathrm{R}=\text { thiazol-2-yl) }\end{array}$ & 9 & 10 & 11 & {$\left[\mathrm{Ag}_{2}(\mu-1)_{2}\right]\left(\mathrm{NO}_{3}\right)_{2} \cdot \mathrm{H}_{2} \mathrm{O}$} \\
\hline empirical formula & $\mathrm{C}_{6} \mathrm{H}_{4} \mathrm{~N}_{2} \mathrm{~S}_{4}$ & $\mathrm{C}_{18} \mathrm{H}_{14} \mathrm{FeS}_{4}$ & $\mathrm{C}_{16} \mathrm{H}_{12} \mathrm{FeN}_{2} \mathrm{~S}_{4}$ & $\mathrm{C}_{24} \mathrm{H}_{16} \mathrm{FeN}_{2} \mathrm{~S}_{4}$ & $\mathrm{C}_{48} \mathrm{H}_{36} \mathrm{Ag}_{4} \mathrm{Fe}_{4} \mathrm{~N}_{12} \mathrm{O}_{14}$ \\
\hline$F_{\mathrm{w}}$ & 232.35 & 414.38 & 416.37 & 516.48 & 1659.77 \\
\hline$T[\mathrm{~K}]$ & $133(2)$ & $153(3)$ & $133(2)$ & $153(2)$ & $153(2)$ \\
\hline crystal system & monoclinic & orthorhombic & triclinic & monoclinic & monoclinic \\
\hline space group & $P 2 / c$ & Fdd 2 & $P \overline{1}$ & $P 2_{1} / c$ & $C 2 / c$ \\
\hline$a[\AA]$ & $5.5034(9)$ & $21.883(11)$ & $6.8474(12)$ & $6.9969(4)$ & $30.442(3)$ \\
\hline$b[\AA]$ & $19.354(3)$ & $19.335(18)$ & $8.0194(16)$ & $10.3383(8)$ & $15.0416(7)$ \\
\hline$c[\AA]$ & $8.5337(14)$ & $8.303(4)$ & $8.3936(16)$ & $30.2641(18)$ & $11.6227(10)$ \\
\hline$\alpha, \beta, \gamma\left[{ }^{\circ}\right]$ & 90, 96.07(1), 90 & $90,90,90$ & $110.72(1), 94.77(2), 97.97(2)$ & $90,103.394(5), 90$ & $90,103.262(7), 90$ \\
\hline$V\left[\AA^{3}\right]$ & $903.9(3)$ & $3513(4)$ & $422.58(14)$ & $2129.6(2)$ & $5180.1(7)$ \\
\hline$Z$ & 4 & 8 & 1 & 4 & 4 \\
\hline$\rho_{\text {calcd }}\left[\mathrm{gcm}^{-3}\right]$ & 1.707 & 1.567 & 1.636 & 1.611 & 2.128 \\
\hline$\mu \cdot\left[\mathrm{mm}^{-1}\right]$ & 0.991 & 1.328 & 1.384 & 1.116 & 2.646 \\
\hline$F(000)$ & 472 & 1696 & 212 & 1056 & 3248 \\
\hline crystal size $[\mathrm{mm}]$ & $0.6 \times 0.09 \times 0.07$ & $0.60 \times 0.31 \times 0.13$ & $0.48 \times 0.20 \times 0.02$ & $0.55 \times 0.26 \times 0.13$ & $0.60 \times 0.17 \times 0.04$ \\
\hline$\theta$ range $\left[{ }^{\circ}\right]$ & $2.10-25.00$ & $2.81-25.00$ & $2.62-25.00$ & $2.09-25.0$ & $1.37-24.63$ \\
\hline reflns collected & 5753 & 5554 & 2760 & 13454 & 15748 \\
\hline independent reflns & 1595 & 1492 & 1402 & 3751 & 4354 \\
\hline$R_{\text {int }}$ & 0.1399 & 0.1060 & 0.0901 & 0.0301 & 0.0723 \\
\hline reflns with $[I>2 \sigma(I)]$ & 1174 & 1424 & 1017 & 3249 & 3264 \\
\hline data/restraints/parameters & $1595 / 0 / 109$ & $1492 / 1 / 100$ & $1402 / 0 / 106$ & $3751 / 0 / 281$ & $4354 / 0 / 389$ \\
\hline GOF on $F^{2}$ & 0.927 & 1.079 & 0.934 & 1.061 & 1.014 \\
\hline$R_{1}[I>2 \sigma(I)] / \mathrm{w} R_{2}$ & $0.0515 / 0.1272$ & $0.0589 / 0.1583$ & $0.0590 / 0.1484$ & $0.0215 / 0.0529$ & $0.0427 / 0.1073$ \\
\hline largest diff. peak/hole $\left[e \cdot \AA^{-3}\right]$ & $0.405 /-0.494$ & $1.476 /-0.761$ & $0.573 /-0.860$ & $0.210 /-0.217$ & $1.038 /-1.178$ \\
\hline
\end{tabular}


surface normal, ${ }^{[5]}$ as expected for the binding of both isocyano groups. On the other hand, in-plane modes such as $\bar{\nu}(\mathrm{NC}), \bar{v}(\mathrm{CC}), \delta(\mathrm{CH})$ and ring distortion modes found in the IR spectrum of neat 1 at 2118, 1543, 1095 and $855 \mathrm{~cm}^{-1}$, respectively, are clearly identified in the spectrum of $\mathbf{1}$ on gold. Interaction with the substrate leads to a strong polarisation of lone pair electron density into the metal and causes a shift of the $\tilde{\mathbf{v}}(\mathrm{NC})$ band from 2118 to $2181 \mathrm{~cm}^{-1}$. This compares well with results obtained with other isocyanides $^{[56]}$ and also with the value of $2226 \mathrm{~cm}^{-1}$ found for $\left[(\mu-1)(\mathrm{AuCl})_{2}\right]_{n}$. There is no indication for any surface-unbound isocyano groups in the film. These conclusions are further corroborated by the nitrogen $K$-edge NEXAFS spectra of film 1 shown in Figure 12, which exhibit a single dis-

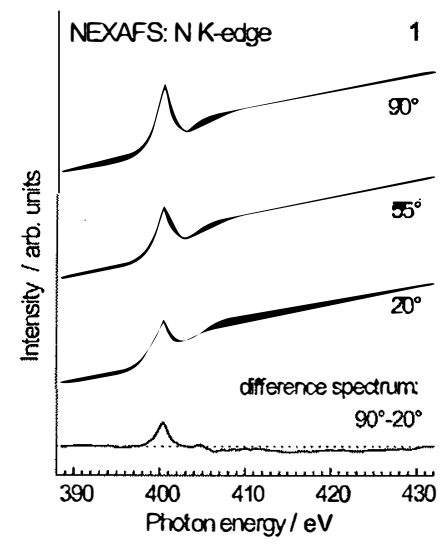

Figure 12. Nitrogen $K$-edge NEXAFS spectra of film 1 acquired at X-ray incidence angles of $90^{\circ}, 55^{\circ}$, and $20^{\circ}$. along with the difference between the spectra acquired at X-ray incidence angles of $90^{\circ}$ and $20^{\circ}$ (bottom curve).

tinct $\pi *(\mathrm{~N} * \mathrm{C})$ resonance at $400.4 \mathrm{eV} .^{[54 ; .57]}$ Features related to the corresponding $\mathrm{NC}$ orbital are also visible at the carbon $K$-edge, as a shoulder at $286.6 \mathrm{eV}{ }^{[54 a .58]}$ Furthermore, the relatively strong $\pi^{*}$-like resonance around $288.6 \mathrm{eV}$ can originate from the conjugation of the $\pi^{*}$ orbitals of the ferrocene nucleus with the $\pi^{*}$ orbitals of the isocyano unit. ${ }^{[5]}$

The NEXAFS difference spectrum of film 1 in Figure 11 shows the pronounced $\pi *\left(4 \mathrm{e}_{\mathrm{Ig}}\right)$ and $\pi *\left(4 \mathrm{e}_{2 \mathrm{u}}\right)$ peaks characteristic of high orientational order. These peaks have the positive sign (we will name it "positive dichroism" in the following text) indicative of a vertical orientation of the cyclopentadienyl decks. Furthermore, a strong positive dichroism is observed for the $\pi^{*}\left(\mathrm{NC}^{*}\right)$ resonance at $286.6 \mathrm{eV}$, which indicates a predominantly vertical orientation of the isocyano headgroups. Since film 1 exhibits the highest degree of orientational order and comprises vertically oriented molecules, we decided to perform the quantitative evaluation of the NEXAFS data and determine the average tilt angle $\alpha$ of the isocyanide headgroup. For the analysis we used the $\jmath *(\mathrm{NC})$ resonances in the carbon and nitrogen $K$-edge spectra. The $\pi *(\mathrm{NC})$ orbitals were considered as plane-type orbitals. Accordingly, $\gamma$ is the angle between the sample normal and the normal to the $\mathrm{J} *(\mathrm{NC})$ plane and thus parallel to the isocyanide tilt angle $\alpha$. The intensities $l$ of these resonances as a function of the X-ray incidence angle were evaluated according to the theoretical expression for a plane-type orbital [Eq. (1)]..$^{[51]}$

$$
\begin{array}{r}
I(\gamma, \theta)=A\left\{P \times\left({ }^{2} / 3\right)\left\{1-\left({ }^{1} / 4\right) \cdot\left(3 \cos ^{2}(\theta-1) \cdot\left(3 \cos ^{2} \gamma-1\right)\right]\right.\right. \\
\left.+(1-P) \times\left[(1 / 2) \cdot\left(1+\cos ^{2} \gamma\right)\right]\right\}
\end{array}
$$

In Equation (1), $A$ is a constant, $P$ is the polarisation factor of the synchrotron light, and $\theta$ is the $\mathrm{X}$-ray incidence angle. To avoid normalisation problems, not the absolute intensities, but the intensity ratios $I(\theta) / I\left(90^{\circ}\right)$ were analysed, ${ }^{[5]]}$ where $I(\theta)$ and $I\left(90^{\circ}\right)$ are the intensities of the $\pi^{* *}(\mathrm{NC})$ resonances at X-ray incidence angles of $\theta$ and $90^{\circ}$, respectively. The resulting values of the average tilt angle $\alpha$ derived on the basis of the $\pi *\left(\mathrm{NC}^{*}\right)$ and $\pi^{*}(\mathrm{~N} * \mathrm{C})$ resonances are $35.1^{\circ}$ and $36.6^{\circ}$, respectively. The accuracy of these values is $\pm 3-$ $5^{\circ}$, which is just the general accuracy of the NEXAFS experiment and data analysis procedure. Within this accuracy, the values obtained from the different absorption edges are essentially identical, which emphasizes their reliability. The average of these two tilt angle values for the $\mathrm{NC}$ axis with respect to the surface normal is $35.9^{\circ}$. Note that the analogous evaluation of the tilt angle of the ferrocene-type units using the dichroism of the $\pi *$ orbitals related to the cyclopentadienyl decks is much more difficult and not completely reliable, since both $\pi *\left(4 \mathrm{e}_{\mathrm{Ig}}\right)$ and $\pi^{*}\left(4 \mathrm{e}_{2 \mathrm{u}}\right)$ are vector orbitals and not only tilt, but also twist of the cyclopentadienyl decks must be considered. In view of the above complications, we decided to consider the linear dichroism of these orbitals as only a qualitative fingerprint for the degree of order in the film.

Film 2: This film differs from film 1 in the attachment of a sulfur atom to each isocyanide moiety, resulting in the formation of isothiocyanato headgroups. According to the XPS (Figure 7 and Table 2) and NEXAFS (Figure 9) data, this modification resulted in a noticeable reduction of the packing density, which is, however, still relatively high as compared to the other films of this study. Both carbon $K$-edge and iron $L$-edge spectra of film 2 exhibit intense resonance structure, characteristic of intact ferrocene-type moieties, suggesting non-dissociative adsorption of the target molecules.

Similar to film 1, a single N 1s XPS emission at $399.8 \mathrm{eV}$ related to the headgroup nitrogen appears in the respective XP spectrum of film $2 .^{[54]}$ Furthermore, only a single doublet at a BE of $161.7 \mathrm{eV}\left(\mathrm{S} 2 \mathrm{p}_{3 / 2}\right)$ is observed in the $\mathrm{S} 2 \mathrm{p} \mathrm{XP}$ spectrum (Figure 8), which is close to the characteristic value for thiolate-type bonding. Since neither additional $\mathrm{N}$ 1s emission peaks nor features characteristic of unbound $\mathrm{S}$ were found, it can be assumed that 2 adopts a bidentate bonding configuration on the gold substrate similar to 1 .

The NEXAFS difference spectrum of film 2 in Figure 11 shows the pronounced $\pi *\left(4 \mathrm{e}_{1 \mathrm{~g}}\right)$ and $\pi *\left(3 \mathrm{e}_{2 \mathrm{u}}\right)$ peaks characteristic of high orientational order. These peaks have the 
positive sign indicative of a vertical orientation of the cyclopentadienyl decks.

Film 3: The carbon $K$-edge NEXAFS spectrum of this film (Figure 10) displays a strong feature at $285.0 \mathrm{eV}$ related to the $\pi_{1} *$ orbital of the phenyl moieties ${ }^{[59]}$ of the diphenylphosphanyl headgroups. The comparably high intensity of this resonance is nicely compatible with the molecular composition, since 3 contains four phenyl moieties. A horizontal ("flat") adsorption geometry of the phenyl rings can be deduced from the strongly negative dichroism of the $\pi_{1}$ * resonance as seen in the difference spectrum. The orientation of the cyclopentadienyl decks, however, cannot be clearly made out from the difference spectra, since the $\pi *\left(4_{\text {leg }}\right)$ feature of ferrocene at $285.6 \mathrm{eV}$ overlaps with the strong $\pi_{1}{ }^{*}$ difference peak of phenyl.

The $\mathrm{P} 2 \mathrm{p}_{3 / 2}$ XP spectrum of film 3 exhibits a single emission at a BE of $131.1 \mathrm{eV}$. This particular BE is commonly related to aromatic diphenylphosphane derivatives which are either unbound ${ }^{[60]}$ or coordinatively bound to zero-valent transition metals in metal complexes. ${ }^{[6]]}$ In view of the relatively high film density and orientational order, it is very likely in our case that most of the diphenylphosphanyl headgroups are characterised by coordination-type attachment to the gold surface. The low Fe intensity observed in the XP $\mathrm{Fe} 2 \mathrm{p}$ spectra together with the comparably high film thickness of $9.6 \AA$ is understandable in view of the sterically demanding headgroups. The surface area occupied by $\mathbf{3}$ in a bidentate binding configuration via its bulky diphenylphosphanyl headgroups is approximately four to five times larger than that of 1 , in agreement with the $\approx 5: 1 \mathrm{Fe} 2 \mathrm{p}$ intensity ratio of $1 / \mathrm{Au}$ and $3 / \mathrm{Au}$. This is in accord with IR spectroscopic measurements by Westermark et al., who found flat adsorption geometries and intact binding of aromatic phosphanes on a variety of coinage metals. ${ }^{[48]}$

Films 4, 5 and 8: The carbon $K$-edge NEXAFS spectra of these thioether-based films (Figure 10) show characteristic spectral features related to the organometallic moiety. In addition, the spectrum of film 5 shows the characteristic $\pi_{1}{ }^{*}$ resonance at $\approx 285 \mathrm{eV}$ related to the terminal phenyl units of the adsorbate molecule. The difference NEXAFS spectra of films 5 and 8 (Figure 11) exhibit a negative dichroism of the ferrocene $\pi *\left(4 \mathrm{e}_{\mathrm{g}}\right)$ feature at $285.6 \mathrm{eV}$, accompanied by the negative dichroism of the $\pi_{1}^{*}$ resonance (phenyl rings) for film 5. Accordingly, the cyclopentadienyl decks (and the phenyl rings in 5) are strongly inclined. The same is presumably true for film $\mathbf{4}$ as well, but it seems to be more disordered than films 5 and $\mathbf{8}$ according to its NEXAFS difference spectrum in Figure 11.

The $S 2 p$ XP spectrum of film 4 exhibits two $S 2 p_{3 / 2.1 / 2}$ doublets at $\mathrm{BEs}$ of $162.0 \mathrm{eV}$ and $163.8 \mathrm{eV}\left(\mathrm{S} 2 \mathrm{p}_{2 / 3}\right)$ related to two different sulfur moieties. The former doublet is commonly assigned to a thiolate-type attachment to gold, which suggests the cleavage of covalent $\mathrm{C}-\mathrm{S}$ bonds for a part of the adsorbate molecules upon their adsorption. Such binding chemistry has been reported before for thioether head- groups in various molecules. ${ }^{[1 \mathrm{~b} .43]}$ The second doublet observed at $163.8 \mathrm{eV}$ is characteristic of unbound or coordination-type bound sulfur in thioethers. ${ }^{[62]}$ The coexistence of thiolate, coordination-type and/or unbound sulfur species might be a reason for the low molecular order in film 4 .

In contrast to film 4, S 2p XP spectra of films 5 and 8 are dominated by the doublet at $163.8 \mathrm{eV}$, which suggests the dominance of weakly bound or unbound adsorbate molecules in the respective films. The intensity of the thiolate-related doublet is very low, which indicates that only a small part of the pristine thioether groups were cleaved upon adsorption. In view of the horizontal orientation of the cyclopentadienyl decks in these films, as derived from the corresponding NEXAFS data (Figure 11), it is very likely that part of the thioether units form coordinative bonds to the surface, whereas the remaining ones are essentially unbound, with the most likely scenario being that the dominant binding configuration on gold is mono- and bidentate for $\mathbf{5}$ and $\mathbf{8}$, respectively.

The overall film quality and packing density differ among films 4,5 , and 8 . While films 4 and 8 show only traces of oxygen in the $\mathrm{O}$ 1s XP spectra and no oxidised iron, film 5 exhibits considerable amounts of oxygen contaminations and oxidised iron (at $\approx 712 \mathrm{eV}$ for $\mathrm{Fe} 2 \mathrm{p}_{3 / 2}$ ), which indicates that a considerable fraction of the organometallic units got oxidised and presumably decomposed in this film. Films 4 and 8 exhibit relatively low Fe 2p XPS signals (Figure 7) suggesting low packing densities in contrast to film $\mathbf{5}$, which has an Fe intensity comparable to the more ordered films 1 and 2 . The $S 2 p$ signal for film 4 is very high compared to the respective iron intensity (Figure 8). This might be explained by unbound anchor groups, which are oriented towards the film surface so that the respective photoemission signal gets less attenuated. The relatively high $S 2 p$ signal observed for film $\mathbf{8}$ is not unexpected since $\mathbf{8}$ contains four sulfur atoms as opposed to only two present in $\mathbf{4}$ and $\mathbf{5}$.

Films 6 and 7: The thiophene-based compounds 6 and 7 exhibit partial molecular decomposition upon adsorption on the gold surface. The $S 2 p$ XPS spectra of these films (Figure 8) show two distinct doublets at $\approx 162 \mathrm{eV}\left(\mathrm{S} 2 \mathrm{p}_{3 / 2}\right.$ ) and at $163.6 \mathrm{eV}$. The former peak can be assigned to thiolate-type sulfur resulting from the cleavage of the $\mathrm{C}-\mathrm{S}$ bond in the thiophene ring, while the latter species can be ascribed to a weakly coordinated or unbound thiophene. [46,e.63] $^{\text {(3) }}$ This conclusion is supported by the carbon $K$-edge NEXAFS spectra of both films 6 and 7 (Figure 10), exhibiting an absorption intensity at $\approx 285.0 \mathrm{eV}$, which has also been found for oligothiophenes and is commonly associated with dissociative adsorption of thiophene, ${ }^{[64]}$ i.e. cleavage of the $\mathrm{C}-\mathrm{S}$ bond in the thiophene ring to form a thiolate-type attachment to gold. The respective feature is more intense in the spectrum of film 7, whereas in the spectrum of film 6 this feature represents only a shoulder of a stronger resonance at $285.6 \mathrm{eV}$, which, in this particular case, is presumably a superposition of the $\pi *\left(4 \mathrm{e}_{1 \mathrm{~g}}\right)$ resonance of ferrocene and the $\pi_{1} *$ resonance of intact thiophene. ${ }^{[51,64]}$ Therefore, 
the position of the sulfur atom in the thiophene ring with respect to the attached ferrocene nucleus is of importance for the chemical stability of the adsorbate molecules upon their adsorption on the gold surface. This difference in the attachment chemistry is surprising in view of the minor structural difference of molecules 6 and $\mathbf{7}$. We note, however, that several authors have pointed out that the binding conformation of thiophene derivatives is strongly influenced by their functional groups. ${ }^{[46 a .63]}$

A decomposition of the thiophene headgroup for part of the adsorbate molecules results in a pronounced chemical heterogeneity of the derived film, which is strongly disordered and presumably contains the adsorbate species in both bidentate and monodentate bonding configuration. In fact, the NEXAFS difference spectra of films 6 and 7 (Figure 11) exhibit a negative dichroism of the $\pi^{*}\left(4 \mathrm{e}_{1 \mathrm{~g}}\right)$ and $\mathrm{J} *\left(3 \mathrm{e}_{2 \mathrm{u}}\right)$ resonances (at $285.6 \mathrm{eV}$ and $287.0 \mathrm{eV}$, respectively) assigned to the cyclopentadienyl decks. Consequently, we can assume that these decks show predominantly horizontal orientation.

According to the Fe 2p XPS data (Figure 7), film 7 exhibits a much lower iron content than film 6. On the other hand, a higher packing density in film 7 as compared to film 6 can be inferred from the film thickness values for these films, being 8.2 and $6.7 \AA$, respectively. It is possible that the molecular decomposition of 7 upon adsorption affects not only the thiophene moiety but also the ferrocene nucleus. In this hypothesis, iron is lost (by desorption) during the film formation process, allowing a denser packing of the residual, sterically less demanding carbon backbone. Furthermore, the Fe $2 \mathrm{p} \mathrm{XP}$ spectrum of film 6 shows a significant amount of oxidised iron ( $38 \%$ of total Fe intensity), which is a signature of oxidised ferrocene-type iron in this film. In contrast, no noticeable amount of oxidised iron was found in film 7 .

In summary, the XPS and NEXAFS data suggest the formation of ferrocene-based, monomolecular films on $\mathrm{Au}(111)$ from the adsorbate molecules 1-8. The attachment of these molecules to the Au substrate occurs in a SAM-like manner, through the specific headgroups, which are isocyano (1), isothiocyanato (2), phosphanyl (3), thioether $(4,5$ and 8$)$, and thienyl (6 and 7). The quality of the resulting films turned out to be rather different. A high packing density and orientational order was only observed for films 1 and $\mathbf{2}$, which exhibit chemisorbed molecules with a predominantly vertical orientation and bidentate binding configuration. These films also show a high degree of chemical homogeneity and can, in view of all above factors, be considered as true SAMs. A relatively high orientational order, chemical homogeneity, and primarily bidentate bonding configuration was also observed in film 3, but this film is characterised by a lower packing density owed to the "flat" adsorption geometry of the bulky $\mathrm{PPh}_{2}$ headgroups. All other films of this study (48) exhibit chemical inhomogeneity, low orientational order and considerable inclination of the film constituents. There are, presumably, both bidentate and monodentate binding configurations in these films. In the case of the thioetherbased films $(4,5$, and 8$), C-S$ bond cleavage was observed upon adsorption for a part of the adsorbate molecules, resulting in the formation of thiolate-anchored moieties, which coexist with more weakly bound molecules anchored to the substrate by coordination-type bonds typical for thioethers. Also for the thiophene-based films (6 and 7), a decomposition of the thiophene headgroups took place upon adsorption for a part of the precursor molecules, resulting in the coexistence of strongly bonded thiophene-derived species and more weakly coordinated pristine molecules in the films. The relative portions of these two fractions were found to depend on the exact position of the thiophene sulfur atom with respect to the ferrocene moiety. Partial oxidation and decomposition of the organometallic moiety in some of the films (especially, in films 5 and 6) cannot be completely excluded.

\section{Conclusions}

We have investigated $1,1^{\prime}$-disubstituted ferrocene derivatives $\left[\mathrm{Fe}\left(\mathrm{C}_{5} \mathrm{H}_{4} \mathrm{X}\right)_{2}\right](\mathbf{1 - 7}, \mathbf{9 - 1 1})$, which contain substituents suitable for binding to a gold surface $\left[X=\mathrm{NC}, \mathrm{NCS}, \mathrm{PPh}_{2}, 2\right.$ thienyl, 3-thienyl, and SR ( $\mathrm{R}=\mathrm{Me}, \mathrm{Ph}$, thiazol-2-yl, benzothiazol-2-yl)]. Compounds 1-7 contain two ligating atoms for surface coordination. These atoms are carbon in the case of the isocyanide 1, phosphorus in case of dppf (3), and sulfur in all other cases. Compounds 9-11 contain four potentially ligating sulfur atoms each, similar to the tetrasubstituted ferrocene derivative 8 , which contains four $\mathrm{SMe}$ groups. The four sulfur atoms of $\mathbf{8}$ are chemically equivalent, which is not the case for the structurally more complicated compounds 9-11. We have investigated film formation on gold (111) substrates by using the comparatively simple bidentate adsorbate species 1-7 and have also studied the simplest of the tetradentate compounds (8) in this respect.

The diisocyano derivative 1 afforded well-defined SAMs of good quality. In contrast, with the notable exception of the isothiocyanato derivative 2 , all sulfur-containing adsorbate species investigated in this study failed to give rise to well-defined SAMs. However, the problems we have encountered with thioether- and thienyl-based anchor groups (especially $\mathrm{C}-\mathrm{S}$ bond cleavage) are not unprecedented (see above), and our findings clearly support the notion that the behaviour of such anchor groups is unreliable in the context of SAM fabrication. In view of these difficulties, we have abstained so far from an analogous in-depth investigation of the tetradentate sulfur ligands 9-11.

The quality of SAMs fabricated from 2 were found to be similar to that of SAMs prepared from 1 . Our observations concerning the isothiocyanato derivative $\mathbf{2}$ indicate that more detailed investigations concerning SAMs based on organic isothiocyanates are mandatory and also augur well for the usefulness of such systems.

SAM formation can be viewed to rely to a large extent on surface coordination chemistry, which is naturally related to molecular coordination chemistry. As a starting point, we have investigated basic aspects of the molecular coordina- 
tion chemistry of $1,1^{\prime}$-diisocyanoferrocene $(\mathbf{1})$, the most intriguing result being the crystal structure of the gold complex $[(\mu-1$

model for the arrangement of $\mathbf{1}$ in SAMs on gold. We have been able to bridge a gap here between surface science and molecular chemistry and envisage extending this further in the future utilising other ligands of this study.

\section{Experimental Section}

General: Synthetic work involving air-sensititve compounds was performed under an atmosphere of dry nitrogen by using standard Schlenk techniques or a conventional glove box. Solvents and reagents were ap propriately dried and purified. 1,1'-Diisocyanoferrocene (1) ${ }^{[6.5]} 1,1^{\prime}$-di (methylthio)ferrocene (4), ${ }^{[11]} 1,1^{\prime}$-di(phenylthio)ferrocene (5) ${ }^{[11]} 1,1^{\prime}$-di(2thienyl)ferrocene (6), $\left.{ }^{\left[{ }^{11}\right]}\right] 1,1^{\prime}, 2,2^{\prime}$-tetra(methyl thio)ferrocene $(8),{ }^{[6]} 2,2^{\prime}$ di(thien-2-yl)disulfide,

phenylphosphoranylidenamino)ferrocene ${ }^{[8 a]}$ were prepared according to or by slight variation of, published procedures. NMR: Varian Unity INOVA $500\left(500.13 \mathrm{MHz}\right.$ for $\left.{ }^{1} \mathrm{H}\right)$; IR: BIO-RAD FTS-40A; elemental analyses: microanalytical laboratories of the University of Kassel and of Imperial College London.

1,1'-Diisothiocyanatoferrocene (2): $\mathrm{CS}_{2}(40 \mathrm{~mL})$ was added to $1,1^{\prime}$ - bis(triphenylphosphoranylidenamino)ferrocene $(1.50 \mathrm{~g}, 2.00 \mathrm{mmol})$ in a thickwalled "RotaflO" ampoule. The suspension was stirred for $3 \mathrm{~h}$ at $90^{\circ} \mathrm{C}$ The resulting clear solution was allowed to cool to room temperature. Volatile components were removed in vacuo. The crude product was dissolved in a minimal amount of dichloromethane and purified by column chromatography (silica gel, $n$-hexane), which afforded an orange, microcrystalline powder. Yield $490 \mathrm{mg}(82 \%)$. ${ }^{1} \mathrm{H}$ NMR $\left(\mathrm{CDCl}_{3}\right): \delta=4.20(\mathrm{~s}$ $4 \mathrm{H}), 4.51 \mathrm{ppm}(\mathrm{s}, 4 \mathrm{H}) ;{ }^{13} \mathrm{C}\left\{{ }^{1} \mathrm{H}\right\} \mathrm{NMR}\left(\mathrm{CDCl}_{3}\right): \delta=67.1,68.0,87.0$, 133.8 ppm; IR: $\bar{\nu}(\mathrm{NCS})=2088 \mathrm{~cm}^{-1}$ (b, vs); elemental analysis (\%) calcd for $\mathrm{C}_{12} \mathrm{H}_{8} \mathrm{FeN}_{2} \mathrm{~S}_{2}$ (300.19): C 48.01, $\mathrm{H} 2.69, \mathrm{~N}$ 9.33; found: $\mathrm{C} 48.13, \mathrm{H}$ 2.69, N 9.39.

1,1'-Di(3-thienyl)ferrocene (7): A $1.60 \mathrm{M}$ solution of $n \mathrm{BuLi}$ in hexane $(15.0 \mathrm{~mL}, 24.0 \mathrm{mmol})$ was added in one portion to finely ground ferrocene $(2.00 \mathrm{~g}, 10.8 \mathrm{mmol})$. The mixture was stirred and TMEDA $(1.37 \mathrm{~g}$ $11.8 \mathrm{mmol}$ ) was added dropwise. Stirring was continued for $14 \mathrm{~h}$. The precipitate (TMEDA adduct of $1,1^{\prime}$-dilithioferrocene, $\approx 3.3 \mathrm{~g}$ ) was filtered off, washed with $n$-hexane $(2 \times 15 \mathrm{~mL})$ and was subsequently suspended $n$-hexane $(15 \mathrm{~mL})$. A solution of $\mathrm{ZnCl}_{2}(2.73 \mathrm{~g}, 20.0 \mathrm{mmol})$ in THF $(15 \mathrm{~mL})$ was added dropwise and the mixture was stirred for $3 \mathrm{~h}$ 3-Bromothiophene $(3.26 \mathrm{~g}, 20.0 \mathrm{mmol})$ and $\left[\mathrm{Pd}\left(\mathrm{PPh}_{3}\right)_{4}\right](0.23 \mathrm{~g}, 0.2 \mathrm{mmol})$ were added sequentially. After $4 \mathrm{~d}$ the mixture was hydrolysed with $1 \mathrm{~N}$ hydrochloric acid $(15 \mathrm{~mL})$ and subsequently extracted with diethyl ether $(3 \times 20 \mathrm{~mL})$ and dichloromethane $(1 \times 30 \mathrm{~mL})$. The combined organic layers were dried with $\mathrm{Na}_{2} \mathrm{SO}_{4}$, which was subsequently removed by filtration. Volatile components were removed in vacuo. The crude product was purified by column chromatography (silica gel, $n$-hexane/dichloromethane 20:1). The first two bands contained ferrocene and (3-thienyl)ferrocene $(460 \mathrm{mg})$. The third band afforded the product as an orange, microcrystalline solid. Yield $2.39 \mathrm{~g}(68 \%)$. ${ }^{1} \mathrm{H}$ NMR $\left(\mathrm{CDCl}_{3}\right): \delta=4.21(\mathrm{~s}, 4 \mathrm{H}$; $\left.\mathrm{C}_{5} \mathrm{H}_{4}\right), 4.39$ (s, $\left.4 \mathrm{H} ; \mathrm{C}_{5} \mathrm{H}_{4}\right), 6.90$ (s. $2 \mathrm{H}$; thienyl), 6.95 ("d", apparent $J=$ $5.0 \mathrm{~Hz}, 2 \mathrm{H}$; thi enyl), $7.18 \mathrm{ppm}\left(\mathrm{m}, 2 \mathrm{H}\right.$; thienyl); $\left.{ }^{13} \mathrm{C} \mid{ }^{1} \mathrm{H}\right\} \mathrm{NMR}\left(\mathrm{CDCl}_{3}\right)$ : $\delta=68.1,69.9,118.0,125.2,126.3,138.6 \mathrm{ppm}$; el emental analysis $(\%) \mathrm{calcd}$ for $\mathrm{C}_{18} \mathrm{H}_{14} \mathrm{FeS}_{2}$ (350.29): C 61.72, H 4.03; found: C 62.64, H 4.53.

1,1'-Di(thien-2-ylthio)ferrocene (9): A solution of di(2-thienyl)disulfide $(2.60 \mathrm{~g}, 11.3 \mathrm{mmol})$ in toluene $(40 \mathrm{~mL})$ was added dropwise with stirring to a suspension of the TMEDA adduct of $1,1^{\prime}$-dilithioferrocene $(\approx 1.7 \mathrm{~g})$ in $n$-hexane $(15 \mathrm{~mL})$, which had been prepared as described above from ferrocene $(1.00 \mathrm{~g}, 5.4 \mathrm{mmol}), n \mathrm{BuLi}(7.5 \mathrm{~mL}$ of a $1.60 \mathrm{M}$ solution in hexane, $12.0 \mathrm{mmol})$ and TMEDA $(0.70 \mathrm{~g}, 6.0 \mathrm{mmol})$. After $14 \mathrm{~h}$ water $(15 \mathrm{~mL})$ was added and stirring was continued for $10 \mathrm{~min}$. The organic layer was separated, washed with water $(2 \times 10 \mathrm{~mL})$ and dried with $\mathrm{MgSO}_{4}$, which was subsequently removed by filtration. Volatile compo- nents were removed in vacuo. The yellow sticky crude product was dissolved in a minimal amount of $\mathrm{CH}_{2} \mathrm{Cl}_{2}$ and purified by col umn chromatography (silica gel, $n$-hexane/dichloromethane 10:1), affording the product as a yellow, microcrystalline solid. Yield $1.40 \mathrm{~g}(68 \%)$. 'H NMR $\left(\mathrm{CDCl}_{3}\right): \delta=4.27\left(\mathrm{~s}, 4 \mathrm{H} ; \mathrm{C}_{5} \mathrm{H}_{4}\right), 4.42\left(\mathrm{~s}, 4 \mathrm{H} ; \mathrm{C}_{5} \mathrm{H}_{4}\right), 6.89(\mathrm{~m}, 2 \mathrm{H}$; thi enyl), 7.04 (d, $J=2.4 \mathrm{~Hz}, 2 \mathrm{H}$; thienyl), $7.23 \mathrm{ppm}(\mathrm{d}, J=5.4 \mathrm{~Hz}, 2 \mathrm{H}$; thienyl): ${ }^{13} \mathrm{C}\left\{{ }^{1} \mathrm{H}\right\}$ NMR $\left(\mathrm{CDCl}_{3}\right): \delta=66.9,74.2,127.2128 .4 \mathrm{ppm}$; elemental analysis (\%) calcd for $\mathrm{C}_{18} \mathrm{H}_{14} \mathrm{FeS}_{4}$ (414.42): C 52.17, H 3.41; found: C 52.23, H 3.35 .

1,1'-Di(thiazol-2-ylthio)ferrocene (10): A solution of di(2-thiazolyl)disulfide $(0.93 \mathrm{~g}, 4.0 \mathrm{mmol})$ in toluene $(20 \mathrm{~mL})$ was added dropwise with stirring to a suspension of the TMEDA adduct of 1,1'-dilithioferrocene $(\approx 0.6 \mathrm{~g})$ in $n$-hexane $(10 \mathrm{~mL})$, which had been prepared as described above from ferrocene $(0.37 \mathrm{~g}, 2.0 \mathrm{mmol}), n \mathrm{BuLi}(2.5 \mathrm{~mL}$ of a $1.60 \mathrm{M}$ solution in hexane, $4.0 \mathrm{mmol})$ and TMEDA $(0.34 \mathrm{~g}, 2.1 \mathrm{mmol})$. After $14 \mathrm{~h}$ water $(10 \mathrm{~mL})$ was added and stirring was continued for $10 \mathrm{~min}$. The organic layer was separated, washed with water $(2 \times 10 \mathrm{~mL})$ and dried with $\mathrm{MgSO}_{4}$, which was subsequently removed by filtration. Volatile components were removed in vacuo. The brownish-yellow sticky crude product was dissolved in a minimal amount of dichloromethane and purified by chromatography (neutral alumina, activity grade II, $n$-hexane/dichloromethane 3:1), affording the product as a dark yellow, microcrystalline solid. Yield $0.32 \mathrm{~g}(38 \%)$. ' $\mathrm{H}$ NMR $\left(\mathrm{CDCl}_{3}\right): \delta=4.45\left(\mathrm{~s}, 4 \mathrm{H} ; \mathrm{C}_{5} \mathrm{H}_{4}\right), 4.61$ $\left(\mathrm{s}, 4 \mathrm{H} ; \mathrm{C}_{5} \mathrm{H}_{4}\right), 7.10(\mathrm{~d}, J=2.9 \mathrm{~Hz}, 2 \mathrm{H}$; thiazolyl), $7.58 \mathrm{ppm}(\mathrm{d}, J=2.8 \mathrm{~Hz}$, $2 \mathrm{H}$; thiazolyl $) ;{ }^{13} \mathrm{C}\left\{{ }^{1} \mathrm{H}\right\} \operatorname{NMR}\left(\mathrm{CDCl}_{3}\right): \delta=69.8,72.6,76.3,119.0,143.1$, $169.2 \mathrm{ppm}$; elemental analysis (\%) calcd for $\mathrm{C}_{16} \mathrm{H}_{12} \mathrm{FeN}_{2} \mathrm{~S}_{4}$ (416.39): $\mathrm{C}$ 46.15, H 2.90, N 6.73; found: C 45.37, H 2.87, N 7.40.

1,1'-Di(benzothiazol-2-ylthio)ferrocene (11): A solution of di(2-benzothiazolyl)disulfide $(6.80 \mathrm{~g}, 20.5 \mathrm{mmol})$ in toluene $(70 \mathrm{~mL})$ was added dropwise with stirring to a suspension of the TMEDA adduct of 1,1'-dilithioferrocene $(\approx 3.3 \mathrm{~g})$ in $n$-hexane $(50 \mathrm{~mL})$, which had been prepared as described above from ferrocene $(2.00 \mathrm{~g}, 10.8 \mathrm{mmol}), n B u L i(15.0 \mathrm{~mL}$ of a $1.60 \mathrm{M}$ solution in hexane, $24.0 \mathrm{mmol})$ and TMEDA $(1.37 \mathrm{~g}, 11.8 \mathrm{mmol})$ After $14 \mathrm{~h}$ water $(50 \mathrm{~mL})$ was added and stirring was continued for $10 \mathrm{~min}$. The dark yellow precipitate was isolated by filtration and dried in vacuo. Its purity turned out to be already $>95 \%$ by NMR spectroscopic analysis. Yield $4.74 \mathrm{~g}(92 \%)$. An analytical sample was obtained by column chromatography (silica gel, $n$-hexane/dichloromethane $3: 1$ ). ${ }^{1} \mathrm{H}$ NMR $\left(\mathrm{CDCl}_{3}\right): \delta=4.59\left(\mathrm{~s}, 4 \mathrm{H} ; \mathrm{C}_{5} \mathrm{H}_{4}\right), 4.70\left(\mathrm{~s}, 4 \mathrm{H} ; \mathrm{C}_{5} \mathrm{H}_{4}\right), 7.23$ ("t", $2 \mathrm{H}$; benzothiazolyl), 7.37 ("t", $2 \mathrm{H}$; benzothiazolyl), $7.63(\mathrm{~d}, J=8.0 \mathrm{~Hz}$ $2 \mathrm{H}$; benzothiazolyl), $7.82 \mathrm{ppm}$ (d, $J=7.7 \mathrm{~Hz}, 2 \mathrm{H}$; benzothiazolyl); $\left.{ }^{13} \mathrm{C} \mid{ }^{1} \mathrm{H}\right\} \mathrm{NMR}\left(\mathrm{CDCl}_{3}\right): \delta=73.0,78.0,82.8,120.8,121.8,124.1,126.1 \mathrm{ppm} ;$ element al analysis (\%) calcd for $\mathrm{C}_{24} \mathrm{H}_{16} \mathrm{FeN}_{2} \mathrm{~S}_{4}$ (516.51): C 55.81, H 3.12, N 5.42; found: C 55.71, H 3.22, N 5.49.

$\left[\mathrm{Ag}_{2}(\boldsymbol{\mu}-\mathbf{1})_{2}\right]\left(\mathrm{NO}_{3}\right)_{2}:$ A solution of silver nitrate $(170 \mathrm{mg}, 1.00 \mathrm{mmol})$ in acetonitrile $(15 \mathrm{~mL})$ was added to a stirred solution of $1,1^{\prime}$-diisocyanoferrocene $(1)(236 \mathrm{mg}, 1.00 \mathrm{mmol})$ in acetonitrile $(50 \mathrm{~mL})$. The mixture was stirred in the dark for $14 \mathrm{~h}$. The product precipitated as shiny golden platelets, which were filtered off, washed with acetonitrile $(5 \mathrm{~mL})$ and diethyl ether $(2 \times 5 \mathrm{~mL})$ and dried in vacuo. Yield $465 \mathrm{mg}(57 \%)$. An analytical sample of the monohydrate was obtained by recrystallisation from dichlormethane. 'H NMR $\left(\mathrm{CDCl}_{3}\right): \delta=4.47$ (" $\mathrm{t}$ ", $\left.4 \mathrm{H}: \mathrm{C}_{5} \mathrm{H}_{4}\right), 5.30 \mathrm{ppm}(" \mathrm{t}$ ", $\left.4 \mathrm{H} ; \mathrm{C}_{5} \mathrm{H}_{4}\right)$; IR: $\tilde{v}(\mathrm{NC})=2193 \mathrm{~cm}^{-1}(\mathrm{vs})$; elemental analysis (\%) calcd for the hydrate $\mathrm{C}_{24} \mathrm{H}_{22} \mathrm{Ag}_{2} \mathrm{Fe}_{2} \mathrm{~N}_{6} \mathrm{O}_{7}$ (833.91): C 33.57, $\mathrm{H}$ 2.66, N 10.08; found: C $33.06, \mathrm{H} 2.43, \mathrm{~N} 9.55$

X-ray crystallography: X-ray crystallographic data for $\left[(\mu-1)\left\{\mathrm{Cr}(\mathrm{CO})_{5}\right\}_{2}\right]$ and $\left[(\mu-1)(\mathrm{AuCl})_{2}\right]_{n}$ have been published previously. ${ }^{(19)} \mathrm{X}$-ray crystallographic data for RSSR ( $\mathrm{R}=$ thiazol-2-yl), 9-11 and $\left[\mathrm{Ag}_{2}(\mu-1)_{2}\right]-$ $\left(\mathrm{NO}_{3}\right)_{2} \cdot \mathrm{H}_{2} \mathrm{O}$ are collected in Table 2 . Data collection was performed by using a Stoe IPDS-II diffractometer with an area detector. Graphitemonochromatised $\mathrm{Mo}_{\mathrm{K} u}$ radiation $(\lambda=0.71073 \AA)$ was used in each case. The data sets are corrected for Lorentz and polarisation effects. A numerical absorption correction was applied, except for $\left[\mathrm{Ag}_{2}(\mu-1)_{2}\right]\left(\mathrm{NO}_{3}\right)_{2} \cdot \mathrm{H}_{2} \mathrm{O}$. The structures were solved by direct methods. The program SHELXS-97 was used for structure solution and refinement was carried out using SHELXL-97 by full-matrix least-squares refinement on $F^{2}$. All non $\mathrm{H}$ atoms were refined anisotropically except atom $\mathrm{C7}$ in 9 which is affected by disorder of the thiophene ring around the 
$\mathrm{C} 1$-S1 axis, and was refined isotropically. Hydrogen atoms were included at calculated positions using a riding model. In $\left[\mathrm{Ag}_{2}(\mu-1)_{2}\right]\left(\mathrm{NO}_{3}\right)_{2} \cdot \mathrm{H}_{2} \mathrm{O}$ the hydrogen atoms of the solvent molecule could not be located and are not included in the model. CCDC 669238, 669239, 669240, 669241, 669242 contain the supplementary crystallographic data for this paper. The se data can be obtained free of charge from The Cambridge Crystallographic Data Centre via www.ccdc.cam.ac.uk/data_request/cif.

Electrochemistry and spectroelectrochemistry: Electrochemistry was performed in a lab-built cylindrical vacuum tight one compartment cell. A spiral shaped $\mathrm{Pt}$ wire and an $\mathrm{Ag}$ wire as the counter and pseudo-reference electrodes are sealed directly into opposite sides of the glass wall, while the respective working electrode ( $\mathrm{Pt}$ or glassy carbon $1.1 \mathrm{~mm}$ polished with 0.25 um diamond paste (Buehler-Wirtz) before each experiment) are introduced via a Teflon screw cap with a suitable fitting. The cell can be attached to a conventional Schlenk line via two side-arms equipped with teflon screw valves and allows experiments to be performed under an atmosphere of argon with approximately $2.5 \mathrm{~mL}$ of analyte solution. $\mathrm{CH}_{2} \mathrm{Cl}_{2}$ was obtained from Fluka (Burdick \& Jackson) and

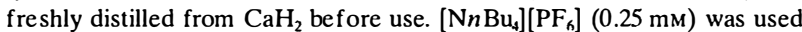
as the supporting electrolyte. All potentials are referenced versus the in ternal ferrocene/ferrocenium couple, to which an appropriate amount of ferrocene was added after all other scans had been recorded. Electrochemical data were acquired by using a computer controlled EG\&G model 273 potentiostat utilising the EG\&G 250 software package. The design of the OTTLE cell follows that of Krejcik et al. ${ }^{[69]}$ It comprises a $\mathrm{Pt}$-mesh working and counter electrode and a thin silver wire as pseudo-reference electrode sandwiched between the $\mathrm{CaF}_{2}$ windows of a conventional liquid IR cell.

Fourier transform infrared spectroscopy of 1: FT-IR spectra of crystalline 1 were recorded by means of a BIO-RAD FTS-40a spectrometer in attenuated total reflection (ATR) geometry. The spectral resolution was $2 \mathrm{~cm}^{-1}$. All bands were assigned according to publications on IR investigations of ferrocene and its derivatives, ${ }^{[19,70]}$ Fourier transform infrared reflection absorption spectroscopic investigations of the monolayer films on gold were performed by using an evacuated Bruker IFS 66v/S spectrometer equipped with a liquid nitrogen cooled mercury cadmium telluride detector. P-polarized light was incident on the sample at an angle of $80^{\circ}$. A total of 2000 scans were measured at a spectral resolution of $2 \mathrm{~cm}^{-1}$.

Film preparation: The gold substrates for film fabrication were prepared by thermal evaporation of $100 \mathrm{~nm}$ gold $(99.99 \%$ purity) onto polished single-crystal silicon (111) wafers (Silicon Sense) primed with a $5 \mathrm{~nm}$ Ti layer for adhesion promotion. The resulting films were polycrystalline with a grain size of $20-50 \mathrm{~nm}$ and predominantly possessed (111) orientation. ${ }^{[1]}$ Films were formed by immersion of freshly prepared gold substrates in $10 \mu \mathrm{m}$ solutions of 1-8 in DMF, ethanol and acetonitrile (1, 2, 4--8) or tolue ne (3) at room temperature for $18 \mathrm{~h}$. After immersion the samples were carefully rinsed with the respective solvent, blown dry with argon and kept in plastic containers backfilled with argon until characterisation.

Near-edge X-ray absorption fine structure spectroscopy: NEXAFS spectroscopic measurements were performed at the HE-SGM beamline of the synchrotron storage ring BESSY II in Berlin, Germany. The spectra were collected at the carbon $K$-edge, nitrogen $K$-edge, and iron $L$-edge with a retardation voltage of $-150 \mathrm{~V}$ for the carbon $K$-edge and $-300 \mathrm{~V}$ for the nitrogen $K$-edge and the iron $L$-edge. Linearly polarised light was used. The energy resolution was approximately $0.4 \mathrm{eV}$ and the incidence angle of the light was varied from $90^{\circ}$ to $20^{\circ}$. Raw NEXAFS spectra were normalised to the incident photon flux by division through a spectrum of a clean, freshly sputtered gold sample. The photon energy scale was referenced to the prominent $\pi_{1}^{*}$ resonance of highly oriented pyrolytic graphite at $285.38 \mathrm{cV}$. Further, the spectra were reduced to the standard form by subtracting line ar pre-edge background and normalizing to the unity edge jump determined by a horizontal plateau $40-50 \mathrm{eV}$ above the absorption edge.

X-ray photoelectron spectroscopy: The XPS measurements were carried out under ultra-high vacuum (UHV) conditions at a base pressure better than $1.5 \times 10^{-9}$ mbar. The experiments were performed using an $\mathrm{Al} \mathrm{K} \boldsymbol{\alpha}$
$\mathrm{X}$-ray source and an LHS1l analyser. The energy resolution was $\approx 0.9 \mathrm{cV}$. The X-ray source was operated at a power of $260 \mathrm{~W}$ and positioned about $1.5 \mathrm{~cm}$ away from the samples. The energy scale was referenced to the $A u 4 f_{7 / 2}$ peak of alkanethiol-coated gold at a binding energy of $84.0-\mathrm{cV}$.

\section{Acknowledgements}

We thank UMICORE AG \& Co. KG for a generous gift of precious metal compounds. Prof. C. Wöll (University of Bochum) for providing us with the experimental equipment for the NEXAFS measurements, and the BESSY II staff for their assistance during these measurements. D.R. is grateful to the Otto-Braun-Fonds for a doctoral fellowship and to the DAAD for a grant supporting a research stay in the group of N.J.L. at Imperial College London. MZ. thanks Prof. M. Grunze (University of Heidelberg) for the support. This work has been supported by the German BMBF (05KS4VHA/4) and the DFG (ZH 63/9-2). Legs shown in the graphical abstract are by courtesy of Dr. T.-C. Auch

[1] For reviews, see: a) S. Onclin, B. J. Ravoo, D. N. Reinhoudt, Angew. Chem. 2005, 117, 6438; Angew. Chem. Int. Ed. 2005, 44, 6282 b) J. C. Love, L. A. Estroff, J. K. Kriebel, R. G. Nuzzo, G. M. Whitesides. Chem. Rev. 2005, 105, 1103; c) F. Schreiber, J. Phys. Condens. Matter 2004, 16, R881; d) F. Schreiber, Prog. Surf. Sci. 2000, 65, 151; e) V. Chechik, R. M. Crooks, C. J. M. Stirling, Adv. Mater. 2000, 12, 1161 ; f) A. Ulman, Chem. Rev. 1996, 96, 1533.

[2] R. G. Nuzzo, D. L. Allara, J. Am. Chem. Soc. 1983, 105, 4481.

[3] G. Trippé, M. Oçafrain, M. Besbes, V. Monroche, J. Lyskawa, F. Le Derf, M. Sallé, J. Becher, B. Colonna, L. Echegoyen, New J. Chem. 2002, 26, 1320.

[4] a) T. Hirsch, M. Zharnikov, A. Shaporenko, J. Stahl, D. Weiss, O.S Wolf beis, V. M. Mirsky, Angew. Chem. 2005, 117, 6933: Angew. Chem. Int. Ed. 2005, 44, 6775; b) K. M. Roth, J. S. Lindsey, D. F. Bocian, W. G. Kuhr, Langmuir 2002, 18, 4030.

[5] For a recent review, see: J. J. Gooding, F. Mearns, W. Yang, J. Liu, Electroanalysis 2003, 15, 81.

[6] T. Weidner, B. Krohn, M. Trojtza, C. Bruhn, D. Rother, U. Sicmeling, F. Trüger, Proc. SPIE-Int. Soc. Opt. Eng. 2006, 6106, 61061S/1.

[7] T. Weidner, A. Krämer, C. Bruhn, M. Zharnikov, A. Shaporenko, U. Siemeling, F. Träger, Dalton Trans. 2006, 2767, and references therein.

[8] a) C. Metallinos, D. Tremblay, F. B. Barrett, N. J. Taylor, J. Organomet. Chem. 2006, 691, 2044; b) A. Tárraga, F. Otón, A. Espinosa M. D. Velasco, P. Molina, D. J. Evans, Chem. Commun. 2004, 458.

[9] Review: a) P. Molina, M. J. Vilaplana, Synthesis 1994, 1197; seminal paper: b) K. It oh, M. Okamura, Y. Ishii, J. Organomet. Chem. 1974, $65,327$.

[10] F. Garnier, A. Yassar, Fr. Demande FR 2668154 A1, 1992.

[11] B. McCulloch, D. L. Ward, J. D. Woollins, C. H. Brubaker, Jr., Organometallics $1985,4,1425$

[12] Y. Xin, H.-M. Liu, W. Zhang, W.-Q. Zhang, Acta Crystallogr. Sect. E 2003, 59, o1153.

[13] W. Zhang, H.-M. Liu, C.-B. Li, W.-Q. Zhang, Acta Crystallogr. Sect E 2003, 59, o26.

[14] P. J. Wheatley, J. Chem. Soc. 1962, 3636

[15] C. J. Matthews, W. Clegg, M. R. J. Elsegood, T. A. Leese, D. Thorp, P. Thornton, J. C. Lockhart, J. Chem. Soc. Dalton Trans. 1996, 1531.

[16] a) Y. V. Zefirov, P. M. Zorkii, Zh. Strukt. Khim. 1976, 17, 745; b) J. Dai, M. Munakata, L.-P. Wu, T. Kuroda-Sowa, Y. Suenaga, Inorg. Chim. Acta 1997, 258, 65.

[17] A. Caballero, V. Lloveras, D. Curiel, A. Tarraga, A. Espinosa, R. García, J. Vidal-Gancedo, C. Rovira, K. Wurst, P. Molina, J. Veciana, Inorg. Chem. 2007, 46, 825.

[18] a) T. Stey, M. Pfeiffer, J. Henn, S. K. Pandey, D. Stalke, Chem. Eur J. 2007, 13, 3636; b) K. Okamoto, T. Kanbara, T. Yamamoto, A 
Wada, Organometallics 2006, 25, 4026; c) G. R. Julius, S. Cronje, A Neveling, C. Esterhuysen, H. G. Raubenheimer, Helv. Chim. Acta 2002, 85, 3737; d) M. Boča, R. Boča, G. Kickelbick, W. Linert, I. Svoboda, H. Fuess, Inorg. Chim. Acta 2002, 3.38, 36.

[19] Part of the results have been briefly communicated: U. Siemeling D. Rother, C. Bruhn, H. Fink, T. Weidner, F. Träger, A. Rothenberger, D. Fenske, A. Priebe, J. Maurer, R. Winter, J. Am. Chem. Soc. $2005,127,1102$.

[20] a) P. J. Shapiro, R. Zehnder, D. M. Foo, P. Perrotin, P. H. M. Budze laar, S. Leitch, B. Twamley, Organometallics 2006, 25, 719; b) T.-C. Holovics, S. F. Deplazes, M. Toriyama, D. R. Powell, G. H. Lushington, M. V. Barybin, Organometallics 2004, 23, 2927; c) M. V. Barybin, T. C. Holovics, S. F. Deplazes, G. H. Lushington, D. R. Powell. M. Toriyama, J. Am. Chem. Soc. 2002, 124, 13668; d) G. R. Knox, P. L. Pauson, D. Wilson, E. Solčániová, Š. Toma, Organometallics 1990, 9, 301; e) T. El-Shihi, F. Siglmüller, R. Herrmann, M. F. N. N. Carvalho, A. J. L. Pombeiro, J. Organomet. Chem. 1987, 335, 239.

[21] C. Elschenbroich, Organometallics, 3rd ed., Wiley-VCH, Weinheim, 2006, pp. 493-494.

[22] a) D. M. P. Mingos, J. Chem. Soc. Dalton Trans. 1996, 561; b) S. S. Pathaneni, G. R. Desiraju, J. Chem. Soc. Dalton Trans. 1993, 319.

[23] See, for example: a) R. L. White-Morris, M. Stender, D. S. Tinti, A. L. Balch, D. Rios, S. Attar, Inorg. Chem. 2003, 42, 3237; b) J. D. E. T. Wilton-Ely, H. Ehrlich, A. Schier, H. Schmidbaur, Helv. Chim. Acta 2001, 84, 3216; c) M. J. Inwin, L. Manojlović-Muir, K. W. Muir, R. J. Puddephatt, D. S. Yufit, Chem. Commun. 1997 219; d) W. Schneider, K. Angermaier, A. Sladek, H. Schmidbaur, Z Naturforsch. B 1995, 51, 790 .

[24] See ref. [22]; for reviews concerning aurophilic bonding, see: a) $\mathrm{P}$ Pyykkö, Angew. Chem. 2004, 116, 4512; Angew. Chem. Int. Ed. 2004, 43, 4412; b) M. C. Gimeno, A. Laguna, Gold Bull. 2003, 36 83; c) J. P. Fackler, Jr., Inorg. Chem. 2002, 41, 6959; d) H. Schmidbaur, Gold Bull. 2000, 33, 3; e) P. Pyykkö, Chem. Rev. 1997, 97, 597; f) H. Schmidbaur, Chem. Soc. Rev. 1995, 2.3, 391.

[25] See, for example: a) R.-Y. Liau, T. Mathieson, A. Schier, R. J. F. Berger, N. Runeberg, H. Schmidbaur, Z. Naturforsch. B 2002, 57 881 ; b) R. E. Bachman, M. S. Fioritto, S. K. Fetics, T. M. Cocker, $J$ Am. Chem. Soc. 2001, 123, 5376; c) T. Mathieson, A. Schier, H Schmidbaur, J. Chem. Soc. Dalton Trans. 2001, 1196; d) R. E. Bachman, S. A. Bodolosky-Bettis, S. C. Glennon, S. A. Sirchio, J. Am. Chem. Soc. 2000, 122, 7146; e) G. Jia, N. C. Payne, J. J. Vittal, R. J. Puddephatt, Organometallics 1993, 12, 4771; f) G. Jia, R. J. Puddephatt, J. J. Vittal, N. C. Payne, Organometallics 1993, 12, 263; g) D. S Eggleston, D. F. Chodosh, R. L. Webb, L. L. Davis, Acta Crystallogr Sect. C 1986, 42, 36; h) S. Esperas, Acta Chem. Scand. Ser. A 1976, $30,527$.

[26] O. Elbjeirami, M. A. Omary, M. Stender, A. L. Balch, Dalton Trans. 2004, 3173.

[27] a) C.-M. Che, H.-K. Yip, W.-T. Wong, T.-F. Lai, Inorg. Chim. Acta 1992, 197, 177; b) C.-M. Che, W.-T. Wong, T.-F. Lai, H.-L. Kwong, $J$. Chem. Soc. Chem. Commun. 1989, 243.

[28] See, for example: a) F. Mendizabal, P. Pyykkö, N. Ru neberg. Chem Phys. Lett. 2003, 370, 733; b) A. Codina, E. J. Fernández, P. J. Jones, A. Laguna, J. M. López-de-Luzuriaga, M. Monge, M. E. Olmos, J. Pérez, M. A. Rodríguez, J. Am. Chem. Soc. 2002, 124, 6781; c) W. J. Hunks, M. C. Jennings, R. J. Puddephatt, Inorg. Chem. 2002, 41, 4590.

[29] D. Braga, L. Maini, F. Paganelli, E. Tagliavini, S. Casolari, F. Grepioni, J. Organomet. Chem. 2001, 637-639, 609.

[30] a) I. Manners, Synthetic Metal-Containing Polymers, Wiley-VCH Weinheim, 2004; b) D. Wöhrlc, A. D. Pomogailo, Metal Complexes and Metals in Macromolecules, Wiley- $\mathrm{VCH}$, Weinheim, 2003 c) R. D. Archer, Inorganic and Organometallic Polymers, WileyVCH, New York, 2001; d) R. P. Kingsborough, T. M. Swager, Prog. Inorg. Chem. 1999, 48, 123

[31] For reviews, see: a) M. Hong, Cryst. Growth Des. 2007, 7, 10 b) R. J. Puddephatt, J. Inorg. Organomet. Polym. Mater. 2006, 15, 371; c) R. J. Puddephatt, Macromol. Symp. 2003, 196, 137; d) R. J. Puddephatt, Coord. Chem. Rev. 2001, 216-217, 313.
[32] F. Klages, M. Monkemeyer, R. Heinle, Chem. Ber. 1952, 85, 109.

[33] Selected recent examples: a) B. Djordjevic, O. Schuster, H. Schmidbaur, Z. Naturforsch. B 2006, 61, 6; b) M.-X. Li. K.-K. Cheung, A Mayr, J. Solid State Chem. 2000, 152, 247.

[34] M. Benouazzane, S. Coco, P. Espinet, J. M. Martín-Alvarez, J. Barberá, J. Mater. Chem. 2002, 12, 691.

[35] S.-L. Zheng, J.-P. Zhang, X.-M. Chen, S.-W. Ng, J. Solid State Chem. 2003, 172, 45, and references thercin.

[36] M.-X. Li, K.-K. Cheung, A. Mayr, J. Solid State Chem. 2000, 152 247.

[37] See, for example: a) R. A. Stein, C. Knobler, Inorg. Chem. 1977, 16 242; b) J. H. Meiners, J. C. Clardy, J. G. Verkade, Inorg. Chem. 1975 14, 632; c) C. S. Gibbons, J. Trotter, J. Chem. Soc. A 1971, 2058; d) J. Cooper, R. E. Marsh, Acta Crystallogr: 1961, 14, 202

[38] See, for example: A. Guitard, A. Mari, A. L. Beauchamp, Y. Dartiguenave, M. Dartiguenave, Inorg. Chem. 1983, 22, 1603.

[39] D. Fortin, M. Drouin, P.D. Harvey, F. G. Herring, D. A. Summers, R. C. Thompson, Inorg. Chem. 1999, 38, 1253.

[40] Y. Yamamoto, K. Aoki, H. Yamazaki, Inorg. Chim. Acta 1983, 68 75 .

[41] D. Käfer, G. Witte, P. Cyganik, A. Terfort, C. Wöll, J. Am. Chem. Soc. 2006, 128, 1723

[42] Seminal paper: J. J. Hickman, P. E. Laibinis, D. I. Auerbach, C. Zou, T. J. Gardner, G. M. Whitesides, M. S. Wrighton, Langmuir 1992. 8 , 357.

[43] Seminal paper: E. B. Troughton, C. D. Bain, G. M. Whit esides, R. G Nuzzo, D. L. Allara, M. D. Porter, Langmuir 1988, 4, 365

[44] M. H. Dishner, J. C. Hemminger, F. J. Feher, Langmuir 1996, 12, 6176.

[45] H. Sakaguchi, H. Matsumura, H. Gong, Nat. Mater. 2004, 3, 551.

[46] See, for example: a) M. Haran, J. E. Goose, N. P. Clote, P. Clancy, Langmuir 2007, 23, 4897, and references therein; b) J. W. Han, J. Noh, Mol. Cryst. Liq. Cryst. 2007, 464, 205; c) E. O. Sako, H. Kondoh, I. Nakai, A. Nambu, T. Nakamura, T. Ohta, Chem. Phys Lett. 2005, 413, 267; d) F. Terzi, R. Seeber, L. Pigani, C. Zanardi, L. Pasquali, S. Nannarone, M. Fabrizio, S. Daolio, J. Phys. Chem. B 2005, 109, 19397; e) J. Noh, E. Ito, T. Araki, M. Hara, Surf. Sci. 2003, 532-535, 1116

[47] a) S.-W. Joo, Surf. Interface Anal. 2006, 38, 173. A recent publication which claims the anchoring of tripodal isothiocyanates onto gold electrodes in fact deals with the isomeric thiocyanates: b) J. A. Camerano, M. A. Casado, U. Hahn, J.-F. Nierengarten, E. Maisonhaute, C. Amatore, New J. Chem. 2007, 31, 1395.

[48] G. Westermark, H. Kariis, I. Persson, B. Liedberg, Colloids Surf. A 1999, 150, 31 .

[49] J. Thome, M. Himmelhaus, M. Zharnikov, M. Grunze, Langmuir $1998,14,7435$.

[50] C. L. A. Lamont, J. Wilkes, Langmuir 1999, 15, 2037.

[51] J. Stöhr, NEXAFS Spectroscopy, Springer Series in Surface Science Vol. 25, Springer, Berlin, 1992.

[52] a) E. Rühl, C. Heinzel, H. Baumgärtel, A. P. Hitchcock, Chem Phys. 1993, 169, 243; b) A. P. Hitchcock, A. T. Wen, E. Rühl, Chem. Phys. 1990, 147, 51.

[53] The assignment has been performed according to refs. [52] and a) E. Ruehl, A. P. Hitchcock, J. Am. Chem. Soc. 1989, 111, 5069 b) A. Shaporenko, K. Rössler, H. Lang, M. Zharnikov, J. Phys. Chem. B 2006, 110, 24621.

[54] a) S. Frey, A. Shaporenko, M. Zharnikov, P. Harder, D. L. Allara, J. Phys. Chem. B 2003, 107, 7716; b) J. F. Moulder, W. E. Stickle, P. E Sobol, K. D. Bomben, Handbook of X-ray Photoelectron Spectroscopy, ed. J. Chastian, Perkin-Elmer Corp., Eden Prairie, MN, 1992.

[55] a) J. T. Young, F. J. Boerio, Z. Zhang, T. L. Beck, Langmuir 1996 12. 1219; b) M. K. Debe, J. Appl. Phys. 1984, 55, 3354.

[56] Recent references: a) D. L. DuBose. R. E. Robinson, T. C. Holovics, D. R. Moody, E. C. Weintrob, C. L. Berrie, M. V. Barybin, Langmuir 2006, 22, 4599; b) J. J. Stapleton, T. A. Daniel, S. Uppili, U. M. Cabarcos, J. Naciri, R. Shashidhar, D. L. Allara, Langmuir 2005, 21, 11061 ; c) K. L. Murphy, W. T. Tysoe, D. W. Bennett, Langmuir 2004, 20, 1732; d) J. I. Henderson, S. Feng, T. Bein, C. P. Kubiak, Lang- 
muir 2000, 16, 6183; e) S. Lin, R. L. McCarley, Langmuir 1999, 15, 151; A. C. Ont ko, R. J. Angelici, Langmuir 1998, 14, 3071.

[57] a) J. M. Ripalda, E. Román, N. Díaz, L. Galán, I. Montero, G. Comelli, A. Baraldi, S. Lizzit, A. Goldoni, G. Paolucci, Phys. Rev. B 1999, 60, R3705; b) I. Shimoyama, G. Wu, T. Sekiguchi, Y. Baba Phys. Rev. B 2000, 62, R6053; c) M. Polcik, M. Kittel, J. T. Hoeft, R. Tcrborg, R. L. Toomes, D. P. Woodruff, Surf. Sci. 2004, 563, 159.

[58] P. A. Stevens, R. J. Madix, J. Stöhr, J. Chem. Phys. 1989, 91, 4338.

[59] a) W. Azzam, B. I. Wehner, R. A. Fischer, A. Terfort, C. Wöll, Langmuir 2002, 18, 7766; b) S. Frey, V. Stadler, K. Heister, W. Eck, M. Zharnikov, M. Grunze, B. Zeysling, A. Terfort, Langmuir 2001, 17, 2408; c) M. Zharnikov, M. Grunze, J. Phys. Condens. Matter 2001 13, 11333; d) A. P. Hitchcock, P. Fischer, A. Gedanken, M. B. Robin. J. Phys. Chem. 1987, 91, 531 .

[60] W. E. Morgan, W. Stec, R. G. Albridge, J. R. Van Wazer, Inorg. Chem. 1971, 10, 926.

[61] See for example: a) B. J. Brisdon, G. F. Griffin, J. Pierce, R. A Walton, J. Organomet. Chem. 1981, 219, 53; b) W. M. Riggs, Anal. Chem. 1972, 44, 830.

[62] a) C.-J. Zhong, R. C. Brush, J. Anderegg, M. D. Porter, Langmuir 1999, 15, 518; b) J. L. Trevor, K. R. Lykke, M. J. Pellin, L. Hanley, Langmuir 1998, 14, 1664.

[63] a) J. Noh, E. Ito, K. Nakajima, J. Kim, H. Lee, M. Hara, J. Phys. Chem. B 2002, 106, 7139.
[64] A. Nambu, H. Kondoh, I Nakai, K. Amemiya, T. Ohta, Surf. Sci. 2003,530,101, and references therein.

[65] D. van Leusen, B. Hessen, Organometallics 2001, 20, 224.

[66] K. Bushell, C. Gialou, C. H. Goh, N. J. Long, J. Martin, A. J.P. White, C. K. Williams, D. J. Williams, M. Fontaine, P. Zanello, J. Organomet. Chem. 2001, 637-639, 418.

[67] B. P. Fedorov, F. M. Stoyanovich, Zh. Obshch. Khim. 1963, 33, 2251.

[68] U. Schmidt, G. Pfleiderer, F. Bartkowiak, Anal. Biochem. 1984, 138 217

[69] M. Krejcik, M. Danek, F. Hartl, J. Electroanal. Chem. 1991, 317, 179.

[70] a) J. N. Willis, Jr., M. T. Ryan, F. L. Hedberg, H. Rosenberg, Spectrochim. Acta A 1968, 24, 1561; b) R. T. Bailey, E. R. Lippincott, Spectrochim. Acta 1965, 21, 389; c) W. K. Winter, B. Curnutte, Jr., S. E Whitcomb, Spectrochim. Acta 1959, 15, 1085; d) E. R. Lippincott, R. D. Nelson, Spectrochim. Acta 1958, 10, 307.

[71] a) C. J. Satterley, K. R. J. Lovelock, I. Thom, V. R. Dhanak, M Buck, R. G. Jones, Surf. Sci. 2006, 600, 4825; b) K. Heister, M. Zharnikov, M. Grunze, L. S. O. Johansson, J. Phys. Chem. B 2001, 105 , 4085 